

\title{
LAS ESCALAS DE SUBMARINOS NUCLEARES EN GIBRALTAR Y ROTA, Y LOS PLANES DE EMERGENCIA RADIOLÓGICA
}

\author{
LUIS ROMERO BARTUMEUS ${ }^{1}$
}

\begin{abstract}
RESUMEN. I.- INTRODUCCIÓN. II.- RELEVANCIA ESTRATÉGICA DE LOS SUBMARINOS. III.- LOS SUBMARINOS NORTEAMERICANOS Y BRITÁNICOS Y SUS ESCALAS EN GIBRALTAR Y ROTA. IV.- LOS PLANES DE EMERGENCIA Y LA POBLACIÓN CIVIL. V.- CONCLUSIONES.
\end{abstract}

\section{ABREVIATURAS Y ACRÓNIMOS}

A2/AD: Anti Acceso/Denegación de Área

AIP: Propulsión Independiente el Aire

AJEMA: Almirante Jefe del Estado Mayor de la Armada (España)

ARA: Armada Argentina

ASW: Guerra Antisubmarina

CEDEX: Centro de Estudios y Experimentación de Obras Públicas (España)

COMNAVACT: Comandante de las Actividades Navales (US Navy)

COVID-19: Coronavirus Diciembre-2019

CSN: Consejo de Seguridad Nuclear (España)

RESUMEN: Cuando un submarino de propulsión nuclear británico o norteamericano recala en el muelle sur del puerto/base naval de Gibraltar, lo habitual es que los grupos ecologistas de la zona colindante española salgan a la palestra protestando por dicha escala y aireando los peligros que comporta esa presencia reiterada. Al margen de los números y ante la repetición de dichas visitas,

1 Trabajo realizado en el marco del Proyecto de Investigación, financiado por la Fundación Pública Andaluza 'Centro de Estudios Andaluces' (PRY205/19): 'La incidencia del 'Brexit' en la cooperación transfronteriza entre Gibraltar-Campo de Gibraltar y Andalucía”, coordinado por la Profesora Inmaculada González García. Período de vigencia, 2020-2022. Luis Romero Bartumeus es periodista, Máster en 'Paz, Seguridad y Defensa’ por el Instituto Universitario ‘General Gutiérrez Mellado' (UNED), Colaborador Honorario del Área de Derecho Internacional Público y Relaciones Internacionales de la Universidad de Cádiz, y miembro del Centro de Estudios Internacionales y Europeos del Área del Estrecho, Grupo de Investigación SEJ-572. 
cabe plantearse cuál es la relevancia de las instalaciones gibraltareñas, y también las de Rota, para la operatividad de dichas plataformas y, más aún, cuál es la importancia, dentro de las marinas de guerra de los países que los poseen, de los submarinos -nucleares o no- en el contexto de la actual situación estratégica internacional.

Veremos qué pasó y qué se hizo cuando en Gibraltar un submarino de la Royal Navy, el 'HMS Tireless', estuvo un año atracado reparando una avería del circuito primario de refrigeración de su reactor nuclear.

El aspecto de la seguridad de la población que vive a muy poca distancia de los atraques de submarinos nucleares la veremos reflejada en el Plan de emergencia nuclear del que dispone Gibraltar y la ausencia del mismo en el lado español de la Verja. Igualmente repasaremos el Plan interior de emergencia nuclear con que cuenta la base de Rota y la ausencia, una vez más, de Plan de emergencia civil para las ciudades que la circundan.

PALABRAS CLAVE: Gibraltar, Rota, Estrecho de Gibraltar, submarinos nucleares, seguridad nuclear, US Navy, Royal Navy, Protección Civil, Emergencia radiológica, Emergencia nuclear.

\title{
THE NUCLEAR SUBMARINE SCALES IN GIBRALTAR AND ROTA, AND THE RADIOLOGICAL EMERGENCY PLANS
}

\begin{abstract}
When a British or North American nuclear-powered submarine docks at the southern dock of the port / naval Base of Gibraltar, it is usual for environmental groups in the neighbouring Spanish area to come to the fore protesting this scale and airing the dangers it entails that repeated presence. Regardless of the numbers and given the repetition of these visits, it is worth considering what is the relevance of the Gibraltar facilities, and also those of Rota, for the operation of these platforms and. Moreover, it is key to stress the importance of the submarines - nuclear or not - for the Navies of the countries that possess them, in the context of the current international strategic situation.
\end{abstract}

This article evaluate what happened and what was done when in Gibraltar a submarine of the Royal Navy, the 'HMS Tireless', was docked for a year repairing a failure in the primary cooling circuit of its nuclear reactor.

The security aspect of the population living a very short distance from the nuclear submarine berths is reflected in the nuclear emergency plan available to Gibraltar and the absence of it on the Spanish side of the Gate. The article will also review the internal nuclear emergency plan available to the US-Spain Rota Base and the absence, once again, of a civil emergency plan for the towns that surround it.

KEY WORDS: Gibraltar, Rota, Strait of Gibraltar, nuclear submarines, nuclear safety, US Navy, Royal Navy, Civil Protection, Radiological emergency, Nuclear emergency. 
No resulta admisible que decisiones que afectan directamente a la seguridad de los españoles, como es la presencia de buques de propulsión nuclear en el puerto de Gibraltar, puedan ser tomadas por terceros al margen de España. La base militar

británica afecta directamente a nuestros intereses legitimos y asi se lo hemos planteado al Reino Unido. Josep Piqué, ministro español de Asuntos Exteriores Congreso de los Diputados, 26/09/2000.

\section{I.- INTRODUCCIÓN}

Los submarinos han pretendido siempre ser unas plataformas sutiles, aunque no fue hasta la aparición del submarino de propulsión nuclear, en la década de los años 50 del siglo XX, que puede hablarse con precisión de submarinos. Hasta entonces era más adecuado definirlos como sumergibles ${ }^{2}$, dado lo limitado del tiempo que podían permanecer bajo el agua y su escasa velocidad en inmersión. Con la aparición de los submarinos nucleares, su tiempo de inmersión pasó a ser ilimitado pues su permanencia bajo el agua solamente está determinada por la resistencia de sus tripulaciones. Además, su velocidad en inmersión se multiplicó por cinco.

Los submarinos pueden dividirse, a grandes rasgos, entre convencionales (generalmente de propulsión diésel-eléctrica) y nucleares. Estos últimos, a su vez, los podemos dividir en de ataque y estratégicos. Los de ataque, conocidos por las siglas $\mathrm{SSN}^{3}$, también definidos como caza submarinos, no suelen estar dotados con armamento nuclear. Los estratégicos, o $\mathrm{SSBN}^{4}$, son los que transportan y pueden llegar a lanzar misiles nucleares intercontinentales y contribuyen a la disuasión estratégica.

\footnotetext{
${ }^{2}$ Worcester, M., «The Role of the Submarine in the Fight for Naval Supremacy in the Pacific», The Institute for Strategic, Political, Security and Economic Consultancy (ISPSW), Berlín. Puede verse en: https://www.files.ethz.ch/isn/126364/Jan11_Role of Submarine.pdf [Visto el 10/10/2020].

3 SSN: Submarine Ship Nuclear (buque submarino nuclear), comúnmente denominado submarino nuclear de ataque o caza submarinos.

${ }^{4}$ SSBN: Submarine Ship Balistic Missil Nuclear (buque submarino nuclear de misiles balísticos). Existe una tercera clase de submarinos nucleares, los SSGN, que en realidad son SSBN reconvertidos en submarinos de ataque, de los que hablaremos más adelante.
} 
Las patrullas de los SSBN, por la naturaleza de su misión principal que es la disuasión estratégica, se desarrollan siempre en inmersión. Lo habitual es que nada más zarpar de sus bases hagan inmersión y no vuelvan a la superficie hasta dos o tres meses después, igualmente frente a la bocana del puerto que les sirve de base, quedando en penumbra cual ha sido su zona de patrulla. Su valor estriba en mantenerse ocultos y a salvo para poder ser utilizados en represalia a un primer ataque nuclear inesperado sobre el territorio de su nación o la de sus aliados.

A los SSN, con misiones múltiples, pese a desarrollar sus patrullas igualmente en inmersión, es más habitual verlos atracar en bases avanzadas. Dado que utilizan dichas escalas para descanso de su personal y avituallamiento, sus patrullas suelen ser más prolongadas.

Los submarinos nucleares de ataque, o SSN, sean británicos o norteamericanos, son los que protagonizan las escalas de este tipo de buques en las bases de Gibraltar y Rota. Rara vez, por no decir nunca, los SSBN realizan escalas ni en estas ni en ninguna otra base. En concreto en Gibraltar solamente se recuerda la escala de un submarino estratégico y fue el 26 de noviembre de 1998, cuando el 'HMS Vanguard' entró en la bahía de Algeciras y posteriormente en la base gibraltareña ${ }^{5}$.

En Rota, debido a su propia historia, sí fue habitual en el pasado la presencia de SSBN norteamericanos, pero eso sucedió porque Rota era la base permanente de un escuadrón de submarinos con misiles 'Polaris', cuando éstos aún no tenían el alcance suficiente para alcanzar sus objetivos desde cualquier océano del planeta. En Europa solamente había otra base utilizada de forma permanente por los Estados Unidos para estas plataformas, la escocesa de Holy Lock. En marzo de 1965 se estableció en Rota el 16 Escuadrón de SSBN de la clase 'Lafayette', aunque el primer submarino había llegado un año antes. El buque logístico que apoyaba dicho despliegue, el 'USS Proteus', también se desplazó a Rota ${ }^{6}$.

Además, en marzo de 1972, Estados Unidos plantea al Gobierno español la necesidad de que Rota pueda constituirse en base provisional de un grupo de SSN, dado que el buque logístico que debe acompañarlo a la base de La ${ }^{5}$ Una colección de imágenes de esta entrada a puerto puede verse en: https://www.youtube. com/watch?v=U9SaHvBOguA [Visto el 30/10/2020].

${ }^{6}$ Romero Bartumeus, L., El Estrecho en la política de seguridad española del siglo XX, Ed. Imagenta, 2003, p. 369. 
Maddalena (Italia) no estaba disponible y se pretendía utilizar mientras tanto el que ya se encontraba en Rota al servicio del $16^{\circ}$ Escuadrón de SSBN. En octubre se autoriza por el Gobierno español dicha solicitud pero por tiempo limitado, hasta junio del año siguiente. Durante ese corto espacio de tiempo, fueron, por lo tanto, dos los escuadrones de submarinos nucleares, uno de SSBN y otro de SSN, los que tuvieron Rota como base 7 . Los SSN abandonan Rota en la fecha prevista (junio de 1973), mientras que los submarinos estratégicos permanecieron hasta 1979, fecha en que se había establecido el abandono de esta localización para los submarinos nucleares norteamericanos en el Tratado de Amistad y Cooperación ${ }^{8}$ firmado entre ambos países en 1976. En realidad, el progreso en el alcance de los misiles balísticos lanzados desde submarinos $(\mathrm{SLBM})^{9}$ hacía ya innecesario contar con bases permanentes avanzadas de SSBN fuera del territorio norteamericano ${ }^{10}$.

Tras que Rota dejara de ser base permanente de submarinos nucleares norteamericanos, éstos no han dejado de recalar en sus muelles de forma esporádica, para descanso de dotaciones y reabastecimiento, aunque al igual que en Gibraltar solamente lo siguen haciendo los SSN.

\section{RELEVANCIA ESTRATÉGICA DE LOS SUBMARINOS}

\section{La disuasión de los submarinos}

Es un lugar común, citado por diversos analistas, señalar la actuación del SSN 'HMS Conqueror' el 2 de mayo de 1981 como una prueba de lo relevante que es el sigilo con que actúan los submarinos y la trascendencia que la sorpresa, y por lo tanto la incertidumbre que generan, puede llegar a aportar al campo

${ }^{7}$ Ibidem, pp. 371-372.

${ }^{8}$ Boletin Oficial del Estado $\mathrm{n}^{\circ}$ 267, de 6 de noviembre de 1976. Disponible en: https://www. boe.es/boe/dias/1976/11/06/pdfs/A21911-21941.pdf [Visto el 01/11/20]. Desde el primer Acuerdo 1953 hasta la actualidad, solamente el de 1976 alcanzó la categoría de Tratado Internacional, aunque la tramitación parlamentaria a la que somete España dichos acuerdos es la misma que si fuera un Tratado Internacional.

${ }^{9}$ SLBM: Submarine-Launched Ballistic Missile (Misil balístico lanzado desde submarino).

${ }^{10}$ Los misiles 'Polaris' habían sido sustituidos por los 'Poseidón' en los primeros submarinos estratégicos, pero fue la introducción de los misiles 'Trident' la que, con un alcance de 7.000 kilómetros en principio, hizo innecesarias las bases avanzadas de SSBN fuera del continente norteamericano. 
de batalla. En esa fecha el citado submarino hundió el crucero 'ARA General Belgrano', en el contexto de la Guerra de Las Malvinas ${ }^{11}$. Como resultado de este único enfrentamiento, y según se puede leer en la 'Joint Doctrine Publication 0-10. UK Maritime Power ${ }^{32}$ de octubre de 2017, la flota de superficie argentina fue retirada del mar «y no participó más en el conflicto».

Una sola actuación, un solo hundimiento, supuso que toda la flota argentina, incluido un portaaviones y varios destructores y corbetas armados con misiles, quedara neutralizada y encerrada en sus puertos base, sin que desempeñara ningún papel en el resto de la campaña, ante la incertidumbre creada por esa acción. El efecto disuasorio fue de una relevancia trascendental. Un ejemplo de que el control del mar, llegado el caso, se encuentra más bajo las aguas que en la superficie ${ }^{13}$. La confirmación de la presencia submarina en torno a Las Malvinas tras el hundimiento del 'ARA General Belgrano', unida a la ausencia de una eficaz guerra antisubmarina (ASW) por parte de la marina argentina, trajo consigo la imposibilidad de que los buques de ésta pudieran intervenir en el conflicto.

En Los fundamentos de la Doctrina Marítima Británica, publicación de 1995, ya superada y revisada dos veces desde entonces, puede leerse un amplio resumen de seis páginas sobre la operación de recuperación de las islas Malvinas, que en las ediciones posteriores de este documento doctrinal queda reducido a unas pocas líneas, aunque insistiendo en la relevancia de esta acción submarina ${ }^{14}$.

La disuasión que provoca la sola sospecha de la presencia de submarinos en una zona o área de operaciones, suele trastocar o complicar los planes de quien quiera asegurar su acceso a ese mar en condiciones ventajosas. El mismo texto doctrinal británico de 2017, referido con anterioridad, señala que los SSN

\footnotetext{
${ }^{11}$ En realidad, la Royal Navy desplazó tres submarinos de ataque a la zona de las Malvinas con motivo de este enfrentamiento, pero solo uno llegó a abrir fuego. La información que proporcionaron para la planificación de la operación anfibia desarrollada por los Royal Marines fue muy relevante.

${ }^{12}$ Ministry of Defence, Joint Doctrine Publication 0-10, UK Maritime Power, $5^{\text {th }}$ Edition, October 2017. Disponible en: https://assets.publishing.service.gov.uk/government/uploads/ system/uploads/attachment data/file/662000/doctrine uk maritime power jdp 0 10.pdf [Visto el 30/10/2020].

${ }^{13}$ Worcester, M., «The Role of the Submarine...», cit. nota 2.

${ }^{14}$ Marina Real Británica (Royal Navy), Los fundamentos de la Doctrina Marítima Británica. BR18067, Servicio de Publicaciones de la Armada (española), 1995, pp. 159-164.
} 
proporcionan «la principal capacidad de negación del mar» ${ }^{15}$, además de su capacidad para recopilar inteligencia de forma encubierta, insertar y recuperar fuerzas de operaciones especiales y contribuir decisivamente a la protección de la fuerza de superficie y a la fuerza submarina de disuasión nuclear propias ${ }^{16}$.

Para los máximos responsables de la Fuerza Submarina de la US Navy, «las Fuerzas Submarinas son fundamentales para proyectar el poder marítimo de los Estados Unidos» a la vez que «juegan un papel integral» en el logro del objetivo de la guerra de maniobra «que potencia todas las funciones de la acción conjunta $\rangle^{17}$. El secretario de Defensa de los Estados Unidos, Mark Esper, al anunciar el 6 de octubre de 2020 el nuevo plan de flota futura de la US Navy, avanzó que la flota de SSN debería alcanzar en el futuro las 70/80 unidades. «Si no hacemos nada más -añadió- la Marina debe comenzar a construir tres submarinos de la clase 'Virginia' al año tan pronto como sea posible». «Si no hacemos nada más -insistió-, deberíamos invertir en submarinos de ataque» ${ }^{18}$. En la actualidad, la capacidad máxima de producción es de dos submarinos al año. El plan de entrega de nuevos submarinos elaborado por la US Navy no prevé que puedan alcanzarse las tres unidades en un solo ejercicio hasta 2024, aunque en ese mismo ejercicio se prevé dar de baja cuatro unidades de la clase anterior ${ }^{19}$.

${ }^{15}$ La negación del mar es una forma anti-acceso y negación de área (A2/AD), ejercida cuando una de las partes impide que un adversario controle un área marítima sin poder controlar esa zona uno mismo.

${ }^{16}$ Reino Unido. Ministerio de Defensa (Ministry of Defence), Joint Doctrine Publication 0-10, UK Maritime Power, $5^{\text {th }}$ Edition, October 2017. Disponible en: https://assets.publishing.service. gov.uk/government/uploads/system/uploads/attachment data/file/662000/doctrine uk maritime power jdp 0 10.pdf [Visto el 30/10/20].

${ }^{17}$ Commander's Intent 3.0. U.S. Submarine Force and Supporting Organizations, 2020 Edition. Puede verse en: https://www.csp.navy.mil/Portals/2/documents/about/SUBLANT-COMMANDERSINTENT3.pdf [Visto el 01/11/20].

${ }^{18}$ ECKSTEIN, M., «SECDEF Esper Calls for 500-Ship Fleet by 2045, With 3 SSNs a Year and Light Carriers Supplementing CVNs». USNI News, 06.10.2020. Puede verse en: https://news. usni.org/2020/10/06/secdef-esper-calls-for-500-ship-fleet-by-2045-with-3-ssns-a-year-andlight-carriers-supplementing-cvns?utm source $=U S N I+N e w s \& u t m$ campaign $=007 \mathrm{eb} 9 \mathrm{f} 708$ USNI NEWS DAILY\&utm medium $=$ email\&utm term $=0$ 0dd4a1450b-007eb9f708$234002629 \& \mathrm{ct}=\mathrm{t}(\mathrm{USNI}$ NEWS DAILY) $\& \mathrm{mc}$ cid $=007 \mathrm{eb} 9 \mathrm{f} 708 \& \mathrm{mc}$ eid $=\mathrm{cbd} 7 \mathrm{fd} 8548$ [Visto el 11/10/20].

${ }^{19}$ Office of the Chief of Naval Operations US Navy, Report to Congress on the Annual LongRange Plan for Construction of Naval Vessels, 9.12.2020. Puede verse en: https://media.defense. 
Pero el relevante papel de los submarinos no se circunscribe exclusivamente a las potencias mundiales, ni tampoco a quienes cuentan con la tecnología nuclear aplicada a los mismos. Para un país tan alejado de nuestro entorno estratégico como puede ser Australia, pero que tiene en el mar todas sus rutas de suministro, «la única plataforma capaz de operar de forma independiente en un área donde su propia nación no controla el mar o el aire es el submarino ${ }^{20}$, coherentes con lo cual la Armada australiana tiene en proyecto duplicar su fuerza submarina, hasta alcanzar la docena de unidades.

El vicealmirante Ray Griggs, que fuera jefe de la Marina Real Australiana, comentando el coste del programa de submarinos en marcha, señaló que había que ponerlo en relación con la inversión o el coste que se «impone a otros para tratar de contrarrestar el efecto de nuestra capacidad submarina» ${ }^{21}$. Además, destacó los submarinos «como un elemento fundamental de nuestra estrategia marítima».

Para el almirante general, jefe del Estado Mayor de la Armada (AJEMA) española, Teodoro López Calderón: «El submarino es una de las unidades de mayor capacidad de disuasión», además de un «arma de capacidad estratégica», ideal para que una Fuerza Naval «llegue a la zona de operaciones con un buen conocimiento del área donde va a operar y del nivel de la amenaza existente» ${ }^{22}$.

Una de las consecuencias inmediatas de la caída de la Unión Soviética fue que su sucesora, Rusia, dejara de tener una Armada operativa y con ella una fuerza submarina activa y presente en los mares. La ruta del Atlántico norte, que ya fue fundamental durante la II Guerra Mundial, se convirtió en una gov/2020/Dec/10/2002549918/-1/-1/0/SHIPBUILDING\%20PLAN\%20DEC\%2020 NAVY OSD OMB FINAL.PDF/SHIPBUILDING\%20PLAN $\% 20 D E C \% 2020$ NAVY OSD OMB FINAL.PDF [Visto el 11/12/20].

${ }^{20}$ Submarine Institut of Australia, «The Importance of Submarines to Australia's National Security», Australian Defence Magazine, Camberra, 9.10.2019. Puede verse en: https://www. australiandefence.com.au/defence/sea/the-importance-of-submarines-to-australia-s-nationalsecurity [Visto el 08/10/20].

${ }^{21}$ VADM, R. G., The Role of Submarines in a Maritime Strategy. ASPI Future Submarine Conference, 9.04.2014. Puede verse en: https://www.navy.gov.au/sites/default/files/documents/CN ASPI Speech 09April2014.pdf [Visto el: 12/10/20].

${ }^{22}$ López Calderón, T., «El Programa S-80 bajo la visión del Almirante General Teodoro López Calderón, Almirante Jefe de Estado Mayor de la Armada española (AJEMA)», Defensa, 30.10.2020. Puede verse en: https://www.defensa.com/programa-submarino-s-80/programas-80-bajo-vision-almirante-general-teodoro-lopez-jefe [Visto el 30/10/20]. 
autopista sin riesgos para las marinas occidentales al desaparecer la presencia o la posible presencia de submarinos rusos. Tan fue así, que la OTAN decidió en junio de 2003 suprimir uno de sus más relevantes mandos estratégicos, el SACLANT, el Mando Supremo Aliado del Atlántico. Por su parte, los Estados Unidos decidieron en 2011 disolver la $2^{a}$ Flota, precisamente la que se ocupaba del Atlántico norte.

Pues bien, primero los Estados Unidos y después la OTAN han vuelto a activar sus respectivos mandos atlánticos tras que Rusia haya regresado a los mares de forma progresiva y proactiva a partir de 2011 y su flota submarina, poco a poco, haya vuelto a las aguas azules ${ }^{23}$. En mayo de 2018 se anunció el restablecimiento de la $2^{\text {a }}$ Flota de la US Navy, que se concretó el 24 de agosto de ese mismo año, aunque no alcanzó su capacidad operativa total hasta diciembre de $2019^{24}$. En junio de 2018, los ministros de Defensa de la OTAN adoptaron una decisión similar al recrear el Mando Atlántico, aunque no se declaró operativo hasta el 17 de septiembre de 2020, bajo la denominación de 'Joint Force Command Norfolk', Mando de la Fuerza Conjunta Norfolk, cuya finalidad será proteger las rutas marítimas entre Europa y América ${ }^{25}$. Ambos mandos, el estadounidense y el aliado, tendrán su cuartel general en Norfolk y el comandante de ambos será el vicealmirante de la US Navy, Andrew Lewis.

\section{2. ¿Vuelta a lo convencional?}

Unas cuarenta marinas de guerra del mundo cuentan con submarinos en estos momentos, entre convencionales y nucleares. Pero solamente diez Taiwán está a punto de sumarse al $\operatorname{club}^{26}$ - son capaces de construir alguno

${ }^{23}$ Se suele denominar así a las aguas profundas que conforman los océanos, alejadas de las costas.

${ }^{24}$ US Fleet Forces Command Public Affairs, «2nd Fleet Declares Full Operational Capability», US Fleet Forces Command, 31.12.2019. Puede verse en: https://www.navy.mil/Press-Office/ Press-Releases/display-pressreleases/Article/2237734/2nd-fleet-declares-full-operationalcapability/ [Visto el 13/11/2020].

25 Joint Force Command Norfolk Public Affairs, «NATO'S New Command in the Atlantic Reaches its first Operational Milestone», US Fleet Forces Command, 17 September 2020. Puede verse en: https://www.usff.navy.mil/Press-Room/News-Stories/Article/2351970/natos-newcommand-in-the-atlantic-reaches-its-first-operational-milestone/ [Visto el 13/11/2020].

26 «Taiwan to start construction of first local-made submarine», Navy Recognition, 2.11.2020. Puede verse en: https://www.navyrecognition.com/index.php/news/ defence-news / 2020/ november/9224-taiwan-to-start-construction-of-first-local-made- 
de los dos modelos o ambos. Las marinas de Estados Unidos, Reino Unido y Francia, han optado por contar exclusivamente con submarinos nucleares en su lista de buques, aunque Francia construye para la exportación unidades convencionales. Otros, como Rusia y China, siguen construyendo y alistando en sus Armadas ambas categorías de submarinos, aunque solamente exportan convencionales. India planifica también un Arma Submarina con ambos tipos de submarinos.

Los países que se dotan de submarinos propulsados por energía nuclear deben realizar una cuantiosa inversión industrial y asumir el elevado coste de cada unidad y su mantenimiento, además de una costosa formación de personal a largo plazo. Empiezan a abundar las opiniones de especialistas occidentales que apuntan la conveniencia de constituir flotas nacionales mixtas con la combinación de submarinos nucleares y convencionales, dado el avance que ha sufrido en las últimas décadas la construcción de la segunda categoría. Cada vez son más las marinas que han incorporado a sus submarinos convencionales la Propulsión Independiente el Aire (AIP) lo que facilita que estas plataformas puedan permanecer en inmersión, sin necesidad de salir a la superficie o hacer 'snorkel' en demanda de oxígeno, entre dos y tres semanas y con un nivel de sigilo muy superior al de los nucleares.

Las capacidades de un submarino caza submarinos de propulsión convencional (SSK) con la incorporación de la AIP y un SSN, se aproximan. China, India, Japón, Alemania, Portugal, Israel, Australia, Singapur, Rusia, Suecia y España, entre otros, se han decidido por la opción de SSK con dicha propulsión independiente del aire. Ningún país que encarga nuevos SSK lo hace sin que tenga la capacidad de embarcar el sistema AIP. Y en lo que no hay comparación posible es en el precio. Los SSN de la clase 'Virginia' de la US Navy se aproximan a los 2.800 millones de dólares por unidad. Un 'Taigei’ japonés de última generación, con AIP, cuesta 722 millones de dólares. Los nuevos SSN $(\mathrm{X})$ norteamericanos, aún solo en la cabeza de los diseñadores, podrían costar entre 3.400 y 5.500 millones de dólares por unidad, según quien haga los cálculos. Además, los submarinos convencionales se han convertido en una pesadilla para quienes deben conseguir su localización y aplicar sobre ellos la guerra antisubmarina, dado que son mucho menos ruidosos que los de propulsión nuclear.

submarine.html?fbclid=IwAR3G-nAZXZLJLNQkBS4Y-VFAvFOelvHgDj02Vq3phE trfuG8C1CA81OhJQ [Visto el 03/11/2020]. 
La capacidad de navegar en inmersión casi en silencio absoluto de un SSK se puso de manifiesto en 2005, cuando en un juego de guerra se expuso a todo un grupo de combate norteamericano, liderado por el portaaviones nuclear 'Ronald Reagan', a la acción de un solo submarino diésel-eléctrico sueco con AIP, el 'HSMS Gotland' y el resultado fue que éste submarino 'hundió' al portaaviones y a varios de sus escoltas, sin que ninguna de las acciones ASW desplegadas por mar y aire llegara a localizarlo antes de que acabara el ejercicio ${ }^{27}$. Bien es cierto que cuando finalizó la prueba había consumido toda su capacidad de navegar en inmersión de forma silenciosa.

Consecuencia directa de este ejercicio fue que la US Navy arrendó el submarino sueco y su tripulación durante dos años para seguir simulando enfrentamientos y conseguir encontrar su talón de Aquiles, dado que sus sensores no eran capaces de localizarlo cuando navegaba en eléctrico.

La Corporación MITRE, en una audiencia en la Cámara de Representantes de los Estados Unidos, defendió en marzo de 2020 los submarinos con propulsión diésel-eléctrica con sistemas AIP como la mejor forma de ampliar la flota submarina, no solamente norteamericana, sino de los aliados en zonas conflictivas a un precio más que asequible. James Holmes, que ocupa la Cátedra 'JC Wylie' de Estrategia Marítima en el 'Naval War College', en un artículo publicado en National Interest, valoró la propuesta y consideró que debía ser tenida en cuenta, afirmando que «los submarinos diésel son una opción para la futura US Navy» ${ }^{28}$.

Pese a que ninguna industria norteamericana construye submarinos convencionales desde hace décadas ${ }^{29}$, Holmes destacó que si es bueno para China construir este tipo de submarinos con fines $\mathrm{A} 2 / \mathrm{AD}^{30}$ en los mares ${ }^{27}$ ROBLIN, S., «Diesel-Powered Submarines Have Become Sweden's Secret Weapon», The National Interest, 1.11.2020. Disponible en: https://nationalinterest.org/blog/reboot/dieselpowered-submarines-have-become-sweden $\% \mathrm{E} 2 \% 80 \% 99$ s-secret-weapon- 171678 ? fbclid=I wAR1Nul2o5VINXYAgZ1OAvN7b58GudZ16QNOdWN5mAMcgUDM9OoyjaC04Fig\&page $=0 \% 2 C 1$ [Visto el 02/11/2020]. Este artículo se publicó por primera vez, en la misma revista, el 30.12.2016.

${ }^{28}$ Holmes, J., «Do Diesel Submarines Have a Future in the U.S. Navy?», National Interest, 10.09.2020. Puede verse en: https://nationalinterest.org/blog/reboot/do-diesel-submarineshave-future-us-navy-168642? page $=0 \% 2 \mathrm{C} 1$ [Visto el 02/10/2020].

${ }^{29}$ El último submarino convencional norteamericano fue desmantelado en 1990.

${ }^{30}$ A2/AD: siglas de Anti Acceso/Denegación de Área. En 2016 el Jefe de Operaciones Navales de la US Navy, el almirante John Richardson, dijo que su servicio dejará de usar este término 
cercanos al continente asiático, debería serlo también para estadounidenses y japoneses «si quieren denegar el acceso que codician», con la ventaja de poder poner muchas más unidades en juego al reducirse en gran medida el coste de fabricación, puesta en servicio y mantenimiento. La excusa de la distancia para el reabastecimiento de combustible, que los SSN no precisan, y que fue planteada por los críticos con esta propuesta, fue descartada por dicho académico, dado que los submarinos nucleares precisan igualmente abastecerse de todo lo que no sea combustible para que su tripulación pueda mantenerse operativa. Los problemas de los submarinos con propulsión nuclear para actuar en zonas litorales, debido a su tamaño y peso que les confiere menor maniobrabilidad y a que las aguas profundas y frías mejoran la refrigeración de sus reactores, son ventajas que aducen los defensores de la opción diésel-eléctrica ${ }^{31}$.

El coste y la tecnología es un enorme hándicap para dotarse de submarinos de propulsión nuclear, al alcance de muy pocos países. Pero es que, además, los sucesivos avances tecnológicos hacen cada vez más probable que la inviolabilidad y la discreción con que actúan los SSN (y los SSBN también) se vea mermada. Y si ésta queda en entredicho, su utilidad también. Como ha escrito James J. Wirtz, decano de la Escuela de Estudios Internacionales de Postgrado en la Naval Postgraduate School' de California, «con suficiente poder computacional, los océanos podrían volverse cada vez más transparentes $»^{32}$. Wirtz destaca que se están produciendo «cambios profundos a intervalos decrecientes, lo que dificulta anticipar desarrollos tecnológicos».

Así pues, la opción por la AIP pone a disposición de muchas más Armadas un submarino con mucha mayor capacidad de pasar desapercibido, a mucho menor coste y con la posibilidad de cumplir muy parecidas misiones que las que realizan los SSN en zonas cercanas al litoral, según los defensores de esta opción. Incluida la posibilidad de lanzar misiles de crucero en inmersión sobre

en aras de la claridad.

${ }^{31}$ Walker, M., y Krusz, A., «There’s a Case for Diesels», Actas US Naval Institute, junio 2018. Puede verse en: https://www.usni.org/magazines/proceedings/2018/june/theres-case-diesels [Visto el 04/11/20].

${ }^{32}$ WirTZ, J. A., «The SSBN and US Nuclear Strategy: The Future of the Maritime Deterrent», The Future of the Undersea Deterrent: A Global Survey, Ed. Australian National University. National Securiry College, 2020. Puede verse en: https://nsc.crawford.anu.edu.au/sites/default/files/ publication/nsc crawford anu edu au/2020-02/the future of the undersea deterrent.pdf [Visto el 02/10/2020]. 
blancos fijos en tierra a una distancia considerable, como ya han demostrado las marinas israelí y argelina, por citar solo las dos que pueden hacerlo en el Mediterráneo. Estados Unidos y Rusia recientemente, en el conflicto sirio, también han dado muestras de este efectivo sistema de ataque.

Sin embargo, el Gobierno de los Estados Unidos sigue sin plantearse la opción SSK. Quienes defienden la opción nuclear destacan que los SSN pueden operar a alta velocidad durante tiempo y alcance ilimitados, circunstancia que los dotados con AIP no pueden igualar, dado que si aumentan su velocidad bajo el agua, que pueden hacerlo, consumen mucho más rápidamente su capacidad de permanecer en inmersión. La necesaria velocidad de proyección de su fuerza submarina, que está presente en varios océanos a la vez, es otro argumento que determina la opción norteamericana por la propulsión nuclear.

Otro problema para los proyectos tan complejos y de tan alto coste, como los de submarinos nucleares, es lo prolongado de su tiempo de diseño y construcción y la velocidad a la que evoluciona la tecnología. La nueva generación de submarinos SSBN norteamericanos y británicos ya se está diseñando, e incluso está iniciada la construcción de las primeras unidades, pero no se espera que el primero entre en operaciones hasta dentro de una década, con el consiguiente riesgo de que, cuando se aproxime su botadura, el entorno estratégico y digital haya alcanzado un nivel tal que lo que hoy son ventajas operativas sean entonces debilidades o hayan quedado obsoletas.

En esa evolución tecnológica que quizás lo cambie todo entran los ya existentes, pero aún con mucho más futuro, vehículos submarinos no tripulados $(\mathrm{UUV})^{33}$. Buena parte de la idea de los futuros SSN (X), que se prevé a día de hoy que sean mucho más grandes que los actuales 'Virginia', es que se conviertan en naves nodriza de $\mathrm{UUV}^{34}$, sin olvidar su armamento propio. Los submarinos no tripulados aligerarían a los SSN $(\mathrm{X})$ de algunas de sus misiones más peligrosas y tediosas. Sin embargo, pese a que pueden llegar a provocar un desequilibrio en zona de operaciones similar al que provocó la aparición del submarino tripulado

\footnotetext{
${ }^{33}$ UUV: Unmanned Underwater Vehicle (Vehículo submarino no tripulado).

${ }^{34}$ Holmes, J., «SSN $(\mathrm{X})$ : Does the U.S. Navy Need a Big and Expensive New Attack Submarine?», The National Interest, 14.11.2020. Puede verse en: https://nationalinterest-org. cdn.ampproject.org/c/s/nationalinterest.org/blog/buzz/ssnx-does-us-navy-need-big-andexpensive-new-attack-submarine-172653?amp\&fbclid=IwAR1tL5v8YJq8tefwVAY8ZvzhPKNPDveBVLFq5piaIEXMIUbtF] U6W2uCw [Visto el 17/11/20].
} 
en su momento, aún deben superar algunos escollos en su desarrollo y doctrina, como son las comunicaciones y la autonomía de su operador ${ }^{35}$.

\section{LOS SUBMARINOS NORTEAMERICANOS Y BRITÁNICOS Y SUS ESCALAS EN GIBRALTAR Y ROTA}

Estados Unidos y el Reino Unido mantienen una estrecha y duradera colaboración en todo lo referido a la fisión del átomo que se remonta a los inicios de la era nuclear, en plena II Guerra Mundial. Todo comenzó con la unificación de los programas ‘Tube Alloys' británico y 'Manhattan' norteamericano para conseguir la primera bomba atómica. Sin embargo la «relación especial» que une a ambos países viene de mucho más lejos y formalmente se estableció en 1901 cuando se firma el Tratado Hay-Paumceforte, por el que el Reino Unido deja manos libres a Estados Unidos para la construcción del canal de Panamá36. Un siglo antes, en 1801, se había producido la primera escala de un buque norteamericano en el Peñón.

Pese a que la colaboración de ambos países en torno a la primera bomba nuclear no estuvo en sus inicios exenta de tensiones y de crisis, la primera y segunda Conferencias de Quebec entre el presidente Roosevelt y el primer ministro Churchill, en agosto de 1943 y septiembre de 1944, fueron clave para eliminar suspicacias y conseguir el objetivo estratégico deseado. Pero estos acuerdos fueron mucho más allá de la consecución de la primera bomba, dado que «Estados Unidos y el Reino Unido se obligaban a compartir todos los descubrimientos en materia nuclear y la colaboración debía proseguir al término de la guerra», ya fuera con fines comerciales o militares ${ }^{37}$.

Pese a que cada uno de estos dos países mantiene sus propios programas de construcción de submarinos de propulsión nuclear y de cabezas nucleares, sin embargo muchas de las características y capacidades de sus respectivos programas y algunos de sus sistemas son similares y en ocasiones idénticos.

\footnotetext{
35 Supervielle, F., «Drones submarinos: dos escollos por salvan», Global Strategy, 28.10.2020. Puede verse en: https://global-strategy.org/drones-submarinos-dos-escollos-por-salvar/ [Visto el 29/10/20].

${ }^{36}$ Liberal Fernández, A., Gibraltar: base militar. El interés anglo-americano por el Peñón, Civitas/ Thomson Reuters, Pamplona, 2009, p. 313.

${ }^{37}$ Watson, P., Historia secreta de la bomba atómica, Crítica, Barcelona, 2020, pp. 362-364.
} 
De hecho, los futuros SSBN de nueva generación tanto norteamericanos, clase 'Columbia', como los británicos, clase 'Dreadnought', «en muchos sentidos son un proyecto conjunto». De la misma manera que los nuevos SSN 'Virginia' norteamericanos y los SSN 'Astute' británicos cuentan con "sistemas idénticos". Además, los submarinos estratégicos de ambos países comparten los SLBM Trident II D5LE y sus sistemas de propulsión ${ }^{38}$.

En julio de 1958, los Estados Unidos y el Reino Unido firmaron un acuerdo que constituía todo un compromiso en el desarrollo de sus respectivas capacidades nucleares submarinas ${ }^{39}$. Este acuerdo, que, enmendado en julio de $2014^{40}$, sigue vigente hoy, establece que «cada parte comunicará e intercambiará información con la otra parte y transferirá materiales y equipos a la otra parte $\rangle^{41}$. En concreto se prevé el intercambio de información clasificada para el desarrollo de planes de defensa, la formación de personal, las capacidades de potenciales enemigos en el empleo de armas atómicas, el desarrollo de sistemas de lanzamiento compatibles con el sistema de armas atómicas y la investigación y diseño de reactores nucleares militares.

El artículo 3 prevé que los Estados Unidos puedan transferir, mediante venta, plantas submarinas de propulsión nuclear y sus componentes, así como comunicar la información necesaria para el diseño, fabricación y operación de plantas submarinas de propulsión nuclear. También se acuerda que Estados Unidos podrá vender uranio enriquecido (U-235) al Reino Unido, necesario para su uso como combustible de la planta de propulsión nuclear. Expresamente señalan en el artículo 5.B que «no habrá transferencia por ninguna de las partes

\footnotetext{
${ }^{38}$ SzONDY, D., «Rising tide: Submarines and the future of undersea warfare»", New Atlas, 05.07.2017. Puede verse en: https:// newatlas.com/future-submarines-modern-warfare/49896/ [Visto el 02/10/2020].

${ }^{39}$ Agreement between the Government of the United Kingdom of Great Britain and Northern Ireland and the Government of the United States of America for Co-operation on the Uses of Atomic Energy for Mutual Defence Purposes, July 3, 1958, Her Majestic's Stationery Office. Recuperado de: https://www. cvce.eu/content/publication/2014/6/12/a1ee4c1f-2166-48f3-a886-2711bd647111/publishable en.pdf [Visto el 19/11/2020].

${ }^{40}$ Agreement Between the United States of America and the United Kingdom of Great Britain and Northern Ireland. Amending the Agreement of July 3, 1958, as Amended, Departament of State (USA). Puede verse en: https://2009-2017.state.gov/documents/organization/242252.pdf [Visto el 19/11/2020].

${ }^{41}$ Ibidem.
} 
de armas nucleares» lo que evita que se incumpla el Tratado de No Proliferación Nuclear, del que ambos países son signatarios ${ }^{42}$.

Por lo que se refiere a las escalas en Gibraltar, ambas marinas utilizan el mismo muelle que tiene capacidad para dos amarres a la vez, denominados atraques 49 y 50 . El muelle sur, que es el reservado para estos menesteres, tiene 1.080 metros de los que los 648 metros situados más al norte son de uso exclusivamente militar, según la minuciosa descripción que hace el capitán de navío Ángel Liberal Fernández en sus trabajos ${ }^{43}$.

Estos muelles están considerados, dentro de la clasificación británica, como muelles Z, es decir, capacitados para atraque de buques de propulsión nuclear, con fines operativos o de descanso de tripulaciones, pero no para reparaciones de su planta nuclear. Sin embargo, la experiencia durante la escala de un año entero del 'HMS Tireless" ${ }^{44}$ demuestra que esta limitación puede ser salvada calificándolos temporalmente como si fueran muelles $\mathrm{X}$, que son los que la Royal Navy considera adecuados para llevar a cabo trabajos de seguridad radiológica. Esta adecuación se consiguió equipando y trasladando desde donde fue necesario el equipo y el personal especializado requerido ${ }^{45}$.

En la Cámara de los Comunes, el por entonces ministro de Estado británico para las Fuerzas Armadas, John Spellar, negó que la base naval de Gibraltar hubiera sido recalificada como muelle $\mathrm{X}$, sino que en base a su consideración como Z "se ha mejorado a la norma necesaria para obtener la aprobación del regulador" y que lo que se había hecho había sido "mejorar la organización

${ }^{42}$ Organismo Internacional de Energía Atómica: Tratado sobre la No Proliferación de las Armas Nucleares. Puede verse en: https://www.iaea.org/sites/default/files/publications/documents/ infcircs/1970/infcirc140 sp.pdf [Visto el 03/12/20].

${ }^{43}$ Liberal Fernández, A., «Gibraltar, base de reparaciones de submarinos nucleares», Blog General Dávil, 8.05.2019. Puede verse en: https:/generaldavila.com/2019/05/08/gibraltar-base-dereparaciones-de-submarinos-nucleares-angel-liberal-fernandez-capitan-de-navio-r/ [Visto el 10/05/18].

${ }^{44}$ Desde el 19 mayo de 2000 y hasta 7 mayo de 2001, el 'HMS Tireless' permaneció atracado en los muelles de Gibraltar debido a que en su tránsito desde el Mediterráneo sufrió una fuga de agua del circuito primario de refrigeración de su reactor, debido a una fisura en dicho circuito.

${ }^{45}$ Liberal Fernández, A., Gibraltar: base militar... cit. nota 36, pp. 142-144. El CN (r) Ángel Liberal recibió una felicitación expresa, por escrito, del ministro de Defensa, Federico TrilloFigueroa, por su asesoramiento durante la escala por avería del 'HMS Tireless' en Gibraltar. Copia de dicha felicitación, que figura en su hoja de servicios, se reproduce en la obra antes citada (p. 409). 
de gestión en Gibraltar y proporcionar el equipo adicional necesario para la reparación" ${ }^{46}$. Este equipo, añadió el ministro, sería desmontado una vez finalizada dicha reparación.

Las escalas habituales en Gibraltar, sin embargo, suelen limitarse a tareas de avituallamiento, descanso de personal y reparaciones que no tienen que ver con los elementos que componen el reactor nuclear, las que podríamos denominar convencionales. También es corriente que los submarinos realicen cargas de misiles de crucero o torpedos de los que arman habitualmente los SSN, ambos con carga convencional.

Respecto a las reparaciones a las que se someten los submarinos en escala, pero que se prolongan a veces hasta dos semanas, o las recargas de armas submarinas, en la mayoría de las ocasiones son fácilmente observables dado que la visión sobre el muelle sur es accesible desde muchos lugares del Peñón y los andamios y los movimientos de operarios y equipos auxiliares que son necesarios pueden ser controlados en la distancia sin dificultad por cualquiera.

Que Gibraltar es un lugar habitual para este tipo de reparaciones y avituallamientos resulta evidente a simple vista, dada la cercanía de los muelles a la ciudad y la necesidad de atravesar zonas civiles para el trasiego de pertrechos desde los túneles del Peñón. Estos trabajos se realizan tanto en submarinos británicos como norteamericanos, sin distinción. Para Ángel Liberal, al que ya hemos citado más arriba y lo haremos más adelante de nuevo, pese a que oficialmente siempre se declara que las escalas son para descanso de dotaciones o bien se las define como «programadas», en realidad el motivo de las entradas «suele ser para reparaciones», que generalmente se centran en el casco y máquinas (ajenas al reactor), equipos auxiliares, sensores y comunicaciones ${ }^{47}$.

El digital español Noticias Gibraltar, en enero de 2020, publicó una serie de tres artículos aportando una serie de datos estadísticos sobre las escalas de submarinos, pero centrándose en los días de permanencia en puerto, destacando que en 2019 se habían batido récords y que éste motivo, las reparaciones, era el que actualmente justificaba la mayoría de las llegadas de submarinos a la base

\footnotetext{
${ }^{46}$ UK Parliament. Hansard. House of Commons Hansard. Written Answers Defence: 06 Novembe 2000, Vol. 356. Puede verse en: https://hansard.parliament.uk/Commons/2000-11-06/ debates/43de8890-7dr8b-4c4b-aa42-85bdb0e8f73f/NuclearSubmarines(Gibraltar) [Visto el 18/11/2020].

${ }^{47}$ Liberal Fernández, A., «Gibraltar, base de reparaciones...» cit. nota 43.
} 
gibraltareña. De hecho, afirmaba que «la base militar de Gibraltar está dedicada a la realización de obras en este tipo de buques» ${ }^{48}$.

\section{Los submarinos norteamericanos}

Los Estados Unidos, como ya se mencionó antes, cuentan solamente con submarinos propulsados por energía nuclear. De los estratégicos de la clase 'Ohio', actualmente en servicio, construyó 18 unidades, de los que cuatro fueron transformados en SSGN ${ }^{49}$ para cumplir los límites consecuencia del Tratado START II y el SORT ${ }^{50}$, para lo cual se desprendieron de los misiles intercontinentales con cabezas nucleares y se les dotó de una enorme capacidad de lanzamiento de misiles de crucero, con cabeza convencional. Por esta circunstancia la flota de SSBN de la US Navy suma hoy catorce unidades. Como ya hemos señalado también más arriba, los SSBN no suelen realizar escalas durante sus patrullas, por lo que no es habitual verlos si no es entrando y saliendo de sus puertos base, dada la naturaleza y la finalidad de sus despliegues. Así pues, estos submarinos no suelen ser vistos recalando en Gibraltar. Sin embargo, un escuadrón de los primitivos SSBN 'Lafayette' sí que tuvo su base en Rota durante las décadas de los años 60 y 70 el siglo pasado, como ya explicamos antes.

Sin embargo, a los SSGN (ex SSBN) sí se les puede ver en ocasiones en estos puertos, como fue el caso del 'USS Georgia' que durante la segunda semana del mes de agosto de 2020 fondeó por un corto espacio de tiempo frente a la base naval de Rota para, según informó el Departamento de Defensa norteamericano, recibir a varios integrantes de la Junta de Examen Nuclear del

\footnotetext{
${ }^{48}$ «Las reparaciones de submarinos nucleares en Gibraltar baten récords en 2019», Noticias Gibraltar, 9.01.2020. Puede Verse en: https://noticiasgibraltar.es/general/noticias/reparaciones-submarinosnucleares-gibraltar-baten-records-2019; Véase también: «Las reparaciones de submarinos nucleares en Gibraltar, en ascenso desde el 'Tireless’», Noticias Gibraltar10.01.2020, en: https:/ / noticiasgibraltar. es/gibraltar/noticias/reparaciones-submarinos-nucleares-gibraltar-ascenso-desde-tireless y «Las reparaciones de submarinos nucleares hacen de Gibraltar un puerto de riesgo», Noticias Gibraltar, 12.01.2020, en: https://noticiasgibraltar.es/gibraltar/noticias/reparaciones-submarinos-nucleareshacen-gibraltar-puerto-riesgo [Vistos el 12/11/2020].

${ }^{49}$ SSGN: Submarine Ship Guided Missile (buque submarino de misiles guiados).

${ }^{50}$ El Tratado de Reducción de Armas Estratégicas II (START II) nunca llegó a entrar en vigor. En su lugar, el Tratado de Reducciones Ofensivas Estratégicas (SORT) de mayo de 2002, también conocido como Tratado de Moscú, entró en vigor en junio de 2003. 
Comando de las Fuerzas de la Flota de Estados Unidos y embarcar repuestos ${ }^{51}$. De igual forma, el 'USS Florida', otro submarino clase Ohio reconvertido en SSGN, recaló en Gibraltar a finales de diciembre de 2019. Lo mismo que hizo casi un año después el SSGN 'USS Seawolf' que primero fondeó por unas horas en bahía el último día de noviembre y días después entró en puerto para permanecer diez días realizando reparaciones y reponiendo torpedos, zarpando el 11 de diciembre de 2020.

La fuerza de SSN en servicio en la US Navy en la actualidad está compuesta por unidades de las clases 'Los Ángeles', 'Seawolf' y 'Virginia', esta última correspondiente a los bloques I a IV. Los bloques son distintas versiones del mismo submarino, que se van actualizado y modificado en sus prestaciones y sistemas conforme pasan los años. El 'USS Delaweare' y el 'USS Vermont' son los más modernos, botados ambos durante la actual pandemia, en el mes de abril de 2020. El primero corresponde al último ejemplar del Bloque III y el segundo al primero del Bloque IV. El segundo de este bloque está previsto que entre en servicio en el verano de 2021 y será el ‘USS Oregón'. El penúltimo submarino norteamericano que recaló en Gibraltar lo hizo en mayo de 2019 y fue el SSN 'USS Olympia', que a finales de octubre de ese mismo año fue dado de baja del servicio de forma permanente. Curiosamente esta escala en Gibraltar se prolongó durante veinte días, según se difundió en la prensa, constituyendo la más prolongada en los últimos veinte años (excepción hecha del 'HMS Tireless' en 2000/2001).

El número de SSN en servicio en la US Navy supera los cincuenta dado que, aunque siguen incorporándose nuevas unidades, otras de la clase 'Los Ángeles' son dadas de baja de forma regular. A partir de 2026 comenzarán a retirarse los únicos cuatro de la clase 'Seawolf' que fueron construidos, al cumplir sus treinta años de servicio. Aunque es previsible que la US Navy reduzca el número de submarinos de ataque hasta 42 en una década, las previsiones son llegar al año 2042 con 60 unidades $^{52}$. Sin embargo, será imposible que se alcance la cifra soñada por el cesado secretario Esper de 70/80 SSN si no se consigue dar de

${ }^{51}$ «El 'USS Georgia' recibe a la Junta de Examen Nuclear en aguas próximas a Rota», Noticias Gibraltar, 13.08.2020. Puede verse en: https://noticiasgibraltar.es/campo-gibraltar/defensa/ uss-georgia-recibe-la-junta-examen-nuclear-aguas-proximas-rota [Visto el 04/11/20].

${ }^{52}$ Eckstein, M., «Navy Confident It Could Build 3 Virginia SSNs a Year, Though More Study Needed On Shipyard Capacity», USNI News, 18.11.2020. Puede verse en: https://news.usni. org/2020/11/18/navy-confident-it-could-build-3-virginia-ssns-a-year-though-more-study- 
alta tres unidades al año, cosa que por el momento no se ha concretado. El muy optimista plan de fuerza futura de la US Navy prevé, sobre el papel, que se alcancen los 70 SSN en 2044 y los 80 en $2051^{53}$. La nueva Administración norteamericana deberá confirmar, o no, los planes establecidos poco antes del cambio de presidente.

\section{Las escalas de los submarinos norteamericanos}

La presencia de submarinos nucleares de la US Navy en Gibraltar ha levantado siempre suspicacias en las autoridades españolas, que interpretan las mismas como una falta de compromiso con la reivindicación española sobre el Peñón. Lo cierto es que estas escalas se mantienen en unas cifras poco significativas, aunque no han desaparecido del todo. Por las filtraciones de 'Wikileaks' de los despachos del Departamento de Estado, sabemos que en junio de 2008 diplomáticos españoles hicieron saber a sus interlocutores norteamericanos su desagrado por dichas escalas ${ }^{54}$.

De la misma forma, y aunque son muy escasas las escalas de buques de otras nacionalidades, se han producido comunicaciones similares a otros países por parte del Gobierno español, sobre todo aliados, respecto a las escalas en Gibraltar de buques de Estado. En cuanto a submarinos, reseñar la última de un submarino convencional holandés, el 'HNLMS Bruinvis', en septiembre de 2016.

Las escalas de submarinos norteamericanos en Gibraltar rara vez, desde hace varias décadas, han superado las dos entradas al año, siendo esta cantidad y la de una sola llegada las cifras más habituales. No es extraño tampoco que haya años en los que no recala ninguno, como 2002, 2009, 2013, 2015 y 2017. Tres entradas se registran en 2001, 2003, 2006 y el 2019, mientras que cuatro entradas solamente se han registrado en 2007 y 2008, siendo ésta la cifra más alta en las últimas dos décadas, según las estadísticas que hemos podido consultar ${ }^{55}$. En

needed-on-shipyard-capacity?utm source $=$ USNI+News\&utm campaign $=782 \mathrm{~d} 21$ aa19USNI NEWS DAILY\&utm medium=email\&utm term $=0$ 0dd [Visto el 18/11/20].

${ }^{53}$ Office of the Chief of Naval Operations US Navy: Report to... cit. nota 19.

${ }^{54}$ Liberal Fernandez, A., «Buques aliados en Gibraltan», Atenea, no 33, febrero de 2012.

${ }^{55}$ Respecto a las estadísticas utilizadas como base para estos cálculos, hemos cruzado varios trabajos a los que hemos podido acceder. De entre los más relevantes destacan: el de Ángel Liberal Fernández, difundido en «Gibraltar, base de reparaciones de submarinos...» cit. y otro es el fichero que mantiene abierto el Área de Medio Ambiente y Litoral de Verdemar-Ecologista 
las dos últimas décadas, las escalas de submarinos norteamericanos en Gibraltar suman unas treintaicinco.

La media de días de escala de los submarinos norteamericanos no llega a la semana, aunque el récord de estancia ininterrumpida en la base gibraltareña - sin contar el 'HMS Tireless'- lo tiene, como ya señalamos más arriba, el 'USS Olympia” con 20 días seguidos en mayo/junio de $2019^{56}$, seguido del 'USS Newport News' que permaneció 18 días amarrado al muelle sur entre enero y febrero de 2016.

Los buques de superficie de la US Navy escalan con menor frecuencia que los submarinos, aunque todos los que lo hacen son de propulsión convencional. Muy lejos queda el año 1968 en que la Sexta Flota al completo visitó la base gibraltareña, teniendo que fondear en la Bahía, ocupando incluso aguas no reclamadas como propias por el Reino Unido.

En el seno de la Alianza Atlántica existen unos documentos denominados STANAG que especifican el acuerdo de los países miembros para implementar un estándar ${ }^{57}$. El $1^{\mathrm{o}}$ de julio de 1994 España suscribió el STANAG 1.100 que establece los procedimientos para las visitas de buques de la OTAN a puertos de naciones OTAN y no OTAN. En él España concretó, para general conocimiento de todos los aliados, unas reservas centradas en poder denegar o modificar en cualquier momento una autorización de escala solicitada, además de «no permitir la escala en puertos españoles a buques que procedan en Acción del Campo de Gibraltar bajo el título «Atraque de Submarinos en Gibraltar» y a cuya organización agradezco me haya dado acceso al mismo. Aunque no coinciden al cien por cien ambos listados, ni otros parciales que he consultado, sí se aproximan mucho y en ocasiones las discrepancias se reducen a que en algunos casos no se contemplan como entradas, y en otros sí, los fondeos en Bahía para avituallamiento o los cambios de tripulación que se realizan navegando por el Estrecho, pero apoyados por la base británica. En todo caso, en el cómputo global de escalas durante las dos décadas de las que existen cifras, desde la avería 'HMS Tireless', las diferencias son mínimas.

${ }^{56}$ Ver los despachos de la Agencia EFE en La Vanguardia los días 15/05/19 y 05/06/19 en, https://www.lavanguardia.com/politica/20190515/462265350708/recala-en-gibraltar-elsubmarino-nuclear-estadounidense-uss-olympia.html y https://www.lavanguardia.com/local/ sevilla/20190605/462695422968/el-submarino-nuclear-uss-olympia-se-marcha-del-puertode-gibraltar.html [Vistos el 12/11/20].

57 STANAG: Acuerdo de Estandarización. Hay más de 1.200 STANAG promulgados en la OTAN. La NSO es la Oficina OTAN de Estandarización que inicia, coordina, apoya y administra las actividades de normalización de la OTAN. Véase: https://www.nato.int/cps/ en/natohq/topics 124879.htm?selectedLocale $=$ en [Visto el 07/11/2020]. 
directamente de Gibraltan» y «no permitir la escala en puertos españoles a los buques que, a continuación de su escala en puerto español, se dirijan directamente a Gibraltar». Aunque el contenido de los STANAG no son de acceso público, pese a contar con la clasificación de unclassified, en este caso el Ministerio de Defensa español introdujo la literalidad de estas reservas, como aclaración al margen, en el documento difundido en abierto que recoge el texto consolidado del Convenio en vigor con los Estados Unidos y sus tres protocolos de enmienda ${ }^{58}$.

En dicho Convenio se estipula que «la antelación mínima para la solicitud de cualquier tipo de escala de buques de propulsión nuclear [Rota es el único puerto español donde se les permite atracar] será la que se comunique a través del Comité Permanente» ${ }^{59}$. Este Comité, compuesto por representantes gubernamentales de ambos países, tiene por misión coordinar el desarrollo del Convenio y resolver las cuestiones que cualquiera de las partes plantee respecto a la aplicación del mismo. Antes de esto, desde julio de 1964, cuando aún no existía el mecanismo de coordinación previsto en posteriores Convenios, las visitas de los buques de guerra de propulsión nuclear necesitaban autorización del Ministerio de Asuntos Exteriores español ${ }^{60}$.

El profesor MARQUinA, en un trabajo de 2004 posteriormente redifundido en 2009, señalaba que España rebajó en su momento la exigencia de notificación por adelantado de 30 a 15 días para los submarinos nucleares que deseasen escalar en Rota, con la intención de evitar las escalas en Gibraltar ${ }^{61}$, cosa que resulta evidente no se consiguió, aunque sí aumentaron las escalas en Rota. Las

\footnotetext{
${ }^{58}$ Convenio de cooperación para la defensa entre el Reino de España y los Estados Unidos de América (y otros documentos relacionados), Ministerio de Defensa, 2016, p. 102. Puede verse en: https://publicaciones.defensa.gob.es/media/downloadable/files/links/c/o/convenio-decooperacio n.pdf [Visto el 14/06/2020].

${ }^{59}$ Ibídem. Anejo 3: «Normas complementarias sobre escalas de buques», punto 6.

${ }^{60}$ Pardo SAnz, R. M., «La política norteamericana de Castiella», en Oreja Aguirre, M. y Sánchez Mantero, R. (Coords.) Entre la Historia y la Memoria. Fernando María Castiella y la Política Exteriores de España. 1957-1969, Real Academia de Ciencias Morales y Políticas, Madrid, 2007, p. 347.

${ }^{61}$ Marquina Barrio, A., «La pista de aterrizaje de Gibraltar y la base militan», en Del Valle Gálvez, A. y González García, I., (eds.), Gibraltar. 300 años, Ed. Servicio de Publicaciones de la Universidad de Cádiz, 2004, p. 188 y del mismo autor, «La pista de aterrizaje de Gibraltar y la base militan», UNISCI Discussion Papers, $\mathrm{n}^{\circ} 19$ (enero 2009), p. 231. Puede verse este último en: https://www.ucm.es/data/cont/media/www/pag-72510/UNISCI $\% 20 D P \% 2019 \% 20-\% 20$ MARQUINA\%20GIBRALTAR.pdf [Visto el 05/11/20].
} 
instrucciones o decisiones del Comité Permanente no se hacen públicas, por lo que no se conoce cuál es el plazo establecido en la actualidad para comunicar la escala de dichos submarinos.

La avería del 'HMS Tireless', que trataremos más ampliamente en otro apartado, trajo consigo la paralización de toda la flota de SSN británica para comprobar si existía la misma falla en todos ellos. La Royal Navy llegó a creer que se trataba de un defecto de fabricación y de ahí su drástica decisión, que recibió críticas en la Cámara de los Comunes, de inmovilizar toda la flota. No se vieron afectados, sin embargo, los submarinos estratégicos. Por ese motivo, el Reino Unido entró en conversaciones con Estados Unidos para intentar cubrir los huecos que dejaban sus submarinos, entre otros la cobertura de sus SSBN durante sus patrullas de disuasión. El secretario de Defensa, Geoffrey Hoon, explicó a los diputados que «la seguridad del elemento de disuasión [los $\mathrm{SSBN]}$ no se verá comprometida ${ }^{62}$. El ministro para las Fuerzas Armadas, Spellar, señaló en la Cámara de los Comunes que «tenemos relaciones estrechas y duraderas con la Marina de los Estados Unidos en estos asuntos y en estos momentos ya estamos entablando conversaciones con ella» ${ }^{63}$.

La situación fue tan delicada que en el Parlamento británico se llegó a sugerir la conveniencia de recuperar los submarinos convencionales de la clase 'Upholder' que se habían dado de baja y ofrecidos en alquiler, con opción de compra, a Canadá. El Ministerio de Defensa desechó dicha posibilidad.

La citada relación especial entre ambos países anglosajones se ha visto recientemente robustecida, si cabe, a finales de octubre de 2020, cuando el jefe de Operaciones Navales de la US Navy, el almirante M. M. Gilday y el primer Lord del Almirantazgo de la Royal Navy, el almirante A.D. Radakin, firmaron una 'Declaración de Intenciones' que compromete a las dos Armadas a superar la interoperabilidad, que hasta ahora había inspirado sus relaciones, para pasar a la intercambiabilidad en investigación y desarrollo, adquisición y evaluación, unidades, pertrechos y operaciones de espectro completo.

En el documento Future Integrated Warfighting: From Interoperable to Interchangeable se afirma que:

${ }^{62}$ UK Parliament. Parliamentary Business. Publications and Records. Hansard. Commons Debates. 26/10/00. Colum. 424. Puede verse en: https://publications.parliament.uk/pa/cm199900/ cmhansrd/vo001026/debtext/01026-18.htm [Visto el 18/11/2020].

${ }^{63}$ Hansard 1803-2005. HC Deb. 24.20.2000. Vol. 355. D. Puede verse en: https://api.parliament. uk/historic-hansard/commons/2000/oct/24/hunter-killer-submarines [Visto el 18/11/2020]. 
[...] debemos esforzarnos en pasar de la interoperabilidad a la intercambiabilidad. Este paso positivo debería permitir que los elementos críticos de la fuerza fuesen intercambiables; desde buques de una marina en la fuerza de tareas de la otra, hasta vehículos tripulados y no tripulados que operen desde las cubiertas de los buques de cada uno para reabastecimiento, reacondicionamiento y reasignación de tareas. Este intercambio de capacidades debe ser inmediato y sin fricciones ${ }^{64}$.

Por estas y otras muchas razones, como por ejemplo que en Gibraltar ambos países comparten, además de muelles de atraque, el beneficio de las instalaciones SIGINT ${ }^{65}$ que el Reino Unido tiene desplegadas, las escalas de los submarinos norteamericanos no es previsible que lleguen a desaparecer.

Para el profesor Luis PÉREZ-PRAT, los estadounidenses puede que estén interesados en la permanencia del Reino Unido en Gibraltar, «a los que resultaría preferible contar con un aliado tradicional en las labores de control de la navegación por el Estrecho» ${ }^{66}$.

Pese a todo, las escalas de submarinos norteamericanos en Rota son igualmente habituales, aunque sin comparación posible con las que realizan los buques de superficie, sobre todo desde que se encuentra destinado en dichas instalaciones de forma permanente un escuadrón de cuatro destructores de la clase 'Arleigh Burke'.

En 2020 han sido cuatro las escalas conocidas de submarinos de la US Navy en la base gaditana, siendo especialmente representativa la realizada por el SSN 'USS Indiana' durante el mes de agosto. Ya en junio este mismo submarino había recalado en la base, calificada por la US Navy como 'refugio seguro' durante la pandemia ${ }^{67}$. Y, precisamente por tener que mantener a la tripulación ${ }^{64}$ Statement of Intent. Future Integrated Warfighting: From Interoperable to Interchangeable. 21.10.2020. Puede verse en: https://media.defense.gov/2020/Oct/21/2002521149/-1/-1/0/STATEMENT $\% 20$ OF $\% 20$ INTENT OCT $\% 2021 \% 202020 . P D F / S T A T E M E N T \% 20 O F \% 20 I N T E N T$ OCT $\% 2021 \% 202020 . P D F$ [Visto el 22/10/20].

${ }^{65}$ SIGINT: Inteligencia de señales. Abarca la inteligencia de comunicaciones y la inteligencia electrónica. Recientemente, el Ministerio de Defensa británico ha invertido dos millones de libras en remozar, acondicionar y mejorar sus instalaciones gibraltareñas de 'Windmill Hill', donde ha centralizado sensores y la recepción de la inteligencia de señales.

${ }^{66}$ Pérez-Prat Durbán, L., «Cuestiones de seguridad y defensa en torno a Gibraltan», en Del Valle Gálvez, A. y González García, I., (eds.), Gibraltar. 300 años... cit., p. 204.

${ }^{67}$ USS 6th Fleet Public Affairs: «USS Indiana Conducts Safe Haven port visit in Rota, Spain», U.S. Naval Forces Europe-Africa / U.S. 6th Fleet, 23.06.2020. Puede verse en: https://www.c6f. navy.mil/Press-Room/News/News-Display/Article/2227427/uss-indiana-conducts-safehaven-port-visit-in-rota-spain/ [Visto el 07/11/2020]. 
a salvo de la COVID-19 durante su periodo de descanso, una estrecha coordinación entre el Commander Task Force (CTF) 69 y los responsables de las instalaciones norteamericanas en Rota, con la colaboración de las autoridades navales españolas, se facilitó lo necesario para que el centenar de tripulantes de este submarino pudieran descansar durante una semana y disfrutar de las instalaciones de la base pero sin entrar en contacto con nadie ajeno a la burbuja creada para conservar su aislamiento.

Las instalaciones de recreo, como la piscina o incluso la playa del interior de la base, se cerraron durante horas para los integrantes del 'USS Indiana', así como el campo de golf. Esta visita sirvió para confirmar la condición de puerto seguro de Rota y sentar las bases para establecer un plan en el que apoyar visitas futuras durante épocas de crisis sanitarias ${ }^{68}$. Este apoyo especial durante la pandemia, como base logística avanzada, se repitió con la tripulación del 'USS Hershel “Woody” Williams', una base marítima expedicionaria a flote, el pasado 22 de octubre ${ }^{69}$ durante su escala en Rota.

Nada que ver con lo sucedido a una parte de la tripulación del SSBN 'HMS Vigilant', de la Royal Navy, que durante una escala a mediados de octubre de 2020 en la base norteamericana de Kings Bay, en Georgia, abandonó su confinamiento y, tras pasar una noche en Florida, 35 de sus integrantes dieron positivo en COVID-19.

Este submarino estratégico, equipado con misiles intercontinentales, estaba realizando trabajos de mantenimiento en los Trident II con que va armado. Precisamente en la base de Kings Bay, Estados Unidos y Gran Bretaña cuentan con un depósito común de misiles que se seleccionan al azar por ambas marinas para integrarlos en sus submarinos estratégicos ${ }^{70}$.

${ }^{68}$ Pollock, C., «Meeting the Mission: Team Rota Supports the Fleet», U.S. Naval Forces EuropeAfrica / U.S. 6th Fleet, 28.08.20. Puede verse en: https://www.c6f.navy.mil/Press-Room/News/ Article/2328380/meeting-the-mission-team-rota-supports-the-fleet// [Visto el 28/08/2020].

${ }^{69}$ NAVSUP FLC Sigonella Public Affairs, «NAVSUP plays key logistics role during USS Hershel "Woody" Williams' port visit in Spain», U.S. Naval Forces Europe-Africa / U.S. 6th Fleet, 10.11.2020. Puede verse en: https://www.c6f.navy.mil/Press-Room/News/News-Display/ Article/2410556/navsup-plays-key-logistics-role-during-uss-hershel-woody-williams-portvisit-in/ [Visto el 10/11/2020].

${ }^{70}$ Lagrone, S., «U.K. Ballistic Missile Sub Crew Suffers COVID-19 Outbreak After Visit to U.S. Sub Base», USNI News, 14.10.2020. Puede verse en: https://news.usni.org/2020/10/14/uk-ballistic-missile-sub-crew-suffers-covid-19-outbreak-after-visit-to-u-s-sub-base [Visto el 31/10/2020]; y Carr, J., "Quarter of crew on $f^{3}$ billion nuclear submarine dubbed 'HMS sex 
La base naval de Rota, en el extremo norte de la bahía de Cádiz, cuenta con 2.300 hectáreas de extensión, perfectamente delimitadas en su perímetro, abarcando terrenos de los municipios de Rota y El Puerto de Santa María. La base, dentro de estos límites, tiene todavía disponible espacio más que suficiente para futuras ampliaciones de servicios y facilidades, lo que sumado a las prestaciones que actualmente ofrece, la convierten en una auténtica base logística avanzada para la US Navy con posibilidades de un mayor desarrollo futuro. A esto hay que sumar la cercanía de la base aérea de Morón que, en ocasiones y en lo que se refiere a sus respectivas pistas de aterrizaje, de las más largas de Europa, actúan de forma complementaria, cubriéndose mutuamente en caso de sufrir alguna contingencia.

La base naval de Rota, desde el punto de vista norteamericano, cuenta con un capitán de navío como comandante de las actividades navales de los Estados Unidos en España (COMNAVACT), con competencia también en Portugal, y dependiente del comandante de la Región de la US Navy para Europa, África Central (EURAFCENT), con cuartel general en Nápoles. Sin embargo, dado que la base es de titularidad exclusivamente española, el comandante de la misma es el vicealmirante jefe del Arsenal de Cádiz. Alrededor de cuarenta mandos de otras tantas actividades se encuentran enmarcados en el despliegue permanente norteamericano en esta base, que totaliza un contingente de unos 2.800 militares en activo ${ }^{71}$. Estos, a su vez, tienen a su cargo unos 3.300 familiares dependientes que viven en las proximidades de la base.

and cocaine' test positive for coronavirus after defying orders and going drinking at bars and strip clubs near US naval base», Daily Mail, 14.10.2020. Puede verse en: https://www.dailymail. co.uk/news/article-8837335/Quarter-crew-3billion-nuclear-submarine-dubbed-test-positivecoronavirus.html [Visto el 30/10/2020].

${ }^{71}$ El Convenio entre el Reino de España y los Estados Unidos de América sobre Cooperación para la Defensa, de 1 de diciembre de 1988, establece en su Anexo 2, punto 3, un nivel total de personal militar estadounidense autorizado en la base de Rota de 5.250. El primer protocolo de enmienda a este Convenio, de 10 de abril de 2002, reduce esa cifra a 4.250 militares. La diferencia entre los militares destinados realmente en Rota y los autorizados es tan grande que permite nuevas incorporaciones sin necesidad de revisar el Convenio en vigor. Disponibles en: https://www.boe.es/boe/dias/1989/05/06/pdfs/A13325-13345.pdf y https://www.boe. es/boe/dias/2003/02/21/pdfs/A07215-07227.pdf [Vistos el 27/12/2020]. La base de Rota, que se diseñó y construyó para dar cabida a las fuerzas norteamericanas y que tardó en ser utilizada en todo su potencial por la Armada española, alberga en la actualidad, entre otras unidades e instalaciones: el Cuartel General de la Flota, el Cuartel General Marítimo de Alta Disponibilidad, el Cuartel General Operacional de la UE de la operación 'Atalanta', el Grupo 
Como elemento más relevante de toda esta actividad cabría destacar el Naval Supply Systems Command Fleet Logistics Center Sigonella - Rota' (NAVSUP FLC Rota), o Mando de Sistemas de Suministro Naval Centro Logístico de la Flota Sigonella-Rota, responsable de ofrecer servicios logísticos y apoyo tanto a la US Navy como a la Guardia Costera y al Mando de Transporte Marítimo Militar, además de a socios y aliados. NAVSUP cuenta con ocho centros logísticos distribuidos por todo el planeta. El de Sigonella, que da servicio a la marina estadounidense en Europa, África y las áreas de operación de la $6^{a}$ Flota, cuenta con dos ubicaciones permanentes, siendo Rota una de ellas. Desde el NAVSUP FLC Rota se proporcionan todo tipo de servicios para mantener la capacidad de combate de las unidades navales, que incluyen un Centro de Soporte Logístico, gestión de la cadena de suministro, contratación de servicios, gestión de materiales peligrosos, de combustible, aceites y lubricantes marinos y de aviación, servicios postales y otros.

Rota constituye una de las dos únicas ubicaciones permanentes de NAVSUP FLC Sigonella, uno de los cinco lugares de apoyo logístico y uno de los tres de apoyo a la OTAN en la zona EURAFCENT de la US Navy ${ }^{72}$.

Para el que fuera comandante de las actividades navales norteamericanas en España en 2015, el capitán de navío Greg S. Pekari, la importancia de la base de Rota «no ha sido nunca tan relevante como hoy en día ${ }^{73}$.

\section{Los submarinos británicos}

El Reino Unido, igual que Estados Unidos, solamente mantiene operativos submarinos de propulsión nuclear en sus dos vertientes: de ataque o SSN y estratégicos o SSBN. El número de submarinos de ambos tipos es muy inferior al de su aliado norteamericano. En la actualidad, la Royal Navy mantiene

Anfibio y de Proyección de la Flota, la 41 a Escuadrilla de Escoltas (fragatas F-80) y la Flotilla de Aeronaves. Más de 4.000 militares españoles están destinados en la base. Véase Ruiz, A., «Las unidades y números de la base de Rota», Diario de Cádiz, 29.03.2019. Disponible en: https:// www.diariodecadiz.es/noticias-provincia-cadiz/unidad-Base-Rota 0 1340866200.html [Visto el 27/12/2020].

${ }^{72}$ NAVSUP FLCS. NAVSUP Fleet Logistic Center Sigonella: https://www.navsup.navy.mil/ public/navsup/flcsi/about/ y NAVSUP FLC Rota: https://www.cnic.navy.mil/regions/ cnreurafcent/installations/ns rota/om/navsup-flc-rota.html [Vistos el 25/12/20].

${ }^{73}$ Romero Batumeus L., «La alargada sombra de la base de Rota», Noticias Gibraltar, 12.03.2018. Disponible en: https://noticiasgibraltar.es/noticias/alargada-sombra-base-rota [Visto el 07/11/2020]. 
activos SSN de dos clases: la 'Trafalgar' y la 'Astute', estando previsto que esta última sustituya a todos los que restan de la primera clase cuando finalice el proyecto de construcción y entrega, en principio previsto para 2026. Entre ambas clases suman en la actualidad siete unidades, de los que tres aún son de la veterana 'Trafalgar'. De los estratégicos cuenta con cuatro unidades de la clase 'Vanguard' que, como ya hemos dicho, arman misiles 'Trident' idénticos a los de sus homólogos norteamericanos. El primero de la nueva clase 'Dreadnought' de SSBN no se espera que entre en servicio hasta dentro de una década, aproximadamente igual que su homólogo norteamericano de la clase 'Columbia'. Son, como en el caso norteamericano, los submarinos SSN los que recalan habitualmente en el muelle sur de Gibraltar.

Resulta relevante destacar que cada vez que las autoridades del Ministerio de Defensa británico tienen ocasión de enumerar cuales son las misiones o las infraestructuras que consideran más relevantes de entre las que disponen en Gibraltar, en los primeros lugares siempre suelen aparecer "las instalaciones de atraque de buques de propulsión nuclear", como hizo en sede parlamentaria el secretario de Defensa Hanley, en $1994^{74}$ o el secretario Hoon, cuando en 2004, en el mismo lugar, señaló que la «capacidad de atraque y el apoyo a los submarinos nucleares seguirá siendo una función básica de Gibraltar» ${ }^{75}$.

No queda fuera de estas consideraciones lo sucedido en 2002, cuando se estaba negociando entre España y Gran Bretaña la posibilidad de compartir la soberanía de Gibraltar ${ }^{76}$. La Royal Navy fue señalada en esa época como la responsable de una carta que el ministro británico de Defensa remitió a su compañero de gabinete y titular del Foreign Office, en la que rechazaba de forma tajante que las negociaciones en curso incluyeran la parte del territorio del Peñón en manos de su Departamento (base naval, aeropuerto y despliegue de sensores de inteligencia, fundamentalmente) y que estas pudieran ser compartidas con España. La exclusión del territorio gibraltareño en manos del Ministerio de Defensa de las negociaciones introdujo un elemento insalvable en el proceso ${ }^{77}$.

\footnotetext{
${ }^{74}$ Hansard (House of Commons Daily Debates). Written Answers to Questions, Thursday 7 July 1994. Column 262. Gibraltar Garrison. Disponible en: http://hansard.millbanksystems.com/ written answers/1994/jul/07/gibraltar-garrison [Visto el 09/11/20].

${ }^{75}$ Citado en Liberal Fernández, A., Gibraltar: base militar... cit, nota 36, p. 77.

${ }^{76}$ HaIn, P., Outside in, Biteback Publishing, Londres, 2012, pp. 274-285.

77 Romero Bartumeus L., «La escala del 'Sceptre'. Aviso a navegantes», Análisis del Real Instituto Elcano, ARI no 25, 28.02.2005. Disponible en: http://realinstitutoelcano. 
Perder la posibilidad de atraque de submarinos o simplemente compartir el control de esa facilidad, estaba detrás de esa queja tan extemporánea, dado que la carta en cuestión fue filtrada a la prensa ${ }^{78}$.

También resulta relevante destacar la susceptibilidad de los responsables de la Royal Navy respecto a lo que consideran algo muy suyo, no en balde lo llevan explotado durante varios siglos. Y lo dejan claro siempre que tienen ocasión, sea quien sea el que lo ponga en duda. A principios de 2005, el ministro principal de Gibraltar, Peter Caruana, implicado como estaba en un proceso de diálogo con las autoridades españolas y británicas, por un lado, y con las autoridades locales del Campo de Gibraltar, por otro, quizás sin valorar exactamente el alcance de sus declaraciones, manifestó a un medio de comunicación español que no se repararían más submarinos nucleares en Gibraltar, refiriéndose al año que el 'HMS Tireless' había pasado reparando su avería en el Peñón.

Sólo quince días después de esas declaraciones, el SSN 'HMS Sceptre' hacía su entrada en el puerto para ser reparado en el muelle sur, si bien en esta ocasión no de ningún componente de su sistema de propulsión nuclear. Aunque esta nueva escala era conocida por las autoridades locales, no parece que supieran que iba a ser sometido a dichos arreglos ni la naturaleza de los mismos.

Caruana no dejó de manifestar su enfado en otra entrevista, también a un medio español, dado que señaló que se había enterado del alcance de la avería del submarino por las declaraciones del titular de Exteriores español. No pasó mucho tiempo hasta que el ministro principal puntualizara sus manifestaciones iniciales, explicando que lo que quiso decir fue que no se realizarían más reparaciones en Gibraltar que tuvieran que ver con los elementos nucleares de los sumergibles y que en absoluto se oponían a la escala del "HMS Sceptre".

La necesidad de la escala y las supuestas averías que sufría el submarino, además de los pocos días que duró su permanencia en Gibraltar, podían ser puestas en duda dado que acababa de zarpar de su base tras un periodo de mantenimiento y se encontraba al comienzo de su patrulla. Fuera cierta o no la necesidad de la entrada a puerto, los responsables de la Royal Navy reafirmaron su potestad de entrar en la base de Gibraltar cuando quisieran y por el motivo

org/wps/wcm/connect/a 7d9f0804f0185cdb9aefd3170baead1/ARI-25-2005-E. pdf?MOD=AJPERES\&CACHEID $=\mathrm{a} 7 \mathrm{~d} 9 \mathrm{f} 0804 \mathrm{f} 0185 \mathrm{cdb} 9 \mathrm{aefd} 3170 \mathrm{baead} 1$ [Visto el $11 / 11 / 2020]$.

${ }^{78}$ The Times, 10.05.2002 y El País, 11.05.2002. 
que consideraran oportuno, sin que tuvieran que tener en cuenta la opinión de nadie, tampoco la de las autoridades gibraltareñas ${ }^{79}$.

\section{Tras el 'Tireless', todo cambió}

El titular del Foreign Office en 2006, Jack Straw, en carta del 27 de febrero dirigida a su homólogo español del momento, Miguel Ángel Moratinos, además de señalar que la reparación del 'HMS Tireless' en Gibraltar, entre 2000 y 2001, había sido un hecho «excepcional», se explaya en consideraciones estratégicas. Straw explica que todos los submarinos británicos están declarados a la OTAN y sus despliegues se realizan en apoyo de ese compromiso. Y añade: «La flexibilidad para su despliegue alrededor del mundo es fundamental para nuestro cometido defensivo en el seno de la OTAN, así como para nuestra propia defensa y, por lo tanto, sirve a los intereses defensivos de nuestros dos países. La base naval de Gibraltar desempeña un importante papel de apoyo a la capacidad global de la flota de submarinos de la Royal Navy» ${ }^{80}$.

El titular de Exteriores británico manifiesta también en la misma carta su compromiso de que España «siempre dispondrá de la debida comunicación relativa a los movimientos de los submarinos del Reino Unido en la zona de Gibraltar»y le recuerda que «tales movimientos son y seguirán siendo notificados a través de los canales establecidos en la OTAN a los que España (y otros miembros de la OTAN) tienen acceso privilegiado». Durante los debates que se suscitaron en el Congreso de los Diputados durante los meses en que el 'HMS Tireless' fue reparado en Gibraltar, así como en distintas respuestas parlamentarias, los ministros de Exteriores y Defensa españoles de la época reconocieron, efectivamente, que el Gobierno español supo de la llegada del 'HMS Tireless' a Gibraltar con antelación ${ }^{81}$. Que las autoridades españolas conocen previamente las visitas de los submarinos nucleares a Gibraltar le fue

${ }^{79}$ Para un repaso detallado de este incidente, ver Romero BArtumeus L., «La escala del 'Sceptre'...» cit. nota 77.

${ }^{80}$ Romero Bartumeus, L., «Lo estratégico en la cuestión de Gibraltan», UNISCI Discussion Papers, $\mathrm{n}^{\circ}$ 12, octubre de 2006. Disponible en: https://www.ucm.es/data/cont/media/www/ pag-72529/UNISCIRomero12.pdf [Visto el 09/11/2020].

${ }^{81}$ «Los ministerios de Asuntos Exteriores y de Defensa españoles han estado puntualmente informados de la avería del submarino nuclear Tireless y de su intención de entrar en Gibraltar». Primeras líneas de la Respuesta del Gobierno a la pregunta, para ser respondida por escrito, número 184/0001527, presentada por el diputado Salvador de la Encina, el 12 de junio de 2020 y respondida el 25 de julio del mismo año. Ver, Diario Oficial de las Cortes Generales. Congreso de los 
confirmado a quien esto firma por un funcionario español que durante años ha tenido que ver con estos asuntos.

La avería del'HMS Tireless' estuvo provocada por una fuga del circuito primario de refrigeración del reactor, cuyo origen estaba en una grieta «localizada en la zona de conexión de la tubería del circuito primario a la línea de subida al presionador $\rangle^{82}$ y que afectaba a la soldadura entre ambas y comprometía la integridad del material base de una de ellas ${ }^{83}$.

Tras esta estancia de un año, su compleja reparación y lo acontecido durante la misma todo cambió. Nada volvió a ser igual. Las escalas que hasta entonces pasaban casi desapercibidas, adquirieron una relevancia pública que hasta ese momento no habían tenido. Es desde esas fechas que los colectivos ecologistas y los responsables políticos españoles de la zona cercana, además de los medios de comunicación, se mantienen pendientes de estas visitas y de las circunstancias que las rodean.

Fue tal la movilización que se produjo durante los meses que el 'HMS Tireless' permaneció reparando en Gibraltar que todas las instituciones públicas de la comarca y de la región se pronunciaron en contra de la decisión adoptada por el Gobierno británico de realizar la reparación en la base gibraltareña, en lugar de trasladar el submarino a su base para llevarla a cabo. El profesor Verdú Baeza considera que este caso supuso «una profunda crisis social en todo el arco de la bahía de Algeciras» ${ }^{84}$, provocando una «movilización social sin precedentes», dejando «un profundo poso de abandono e inseguridad entre la población» ${ }^{85}$.

Diputados. Serie D, n 39, de 29 de junio de 2000, Pág. 97 y Serie D, no 55, de 14 de septiembre de 2000, Pág. 313.

${ }^{82}$ InformedelConejode SeguridadNuclearalCongresodelos DiputadosyalSenado. Resumenaño2000. Disponible en: https://www.csn.es/documents/10182/13529/Informe+anual $+2000+\% 28$ resumen $\% 29$ [Visto el 09/11/2020].

${ }^{83}$ Esta concreción de la avería está extraída de los informes publicados por la Dirección General de Protección Civil, del Ministerio del Interior español, durante el tiempo de la reparación. Citado por Verdú BAeza J., «TJCE-Sentencia de 09.03.2006, Comisión/Reino Unido, C-65/04, Tireless - Energía Nuclear y usos militares en el Tratado EURATOM», Revista de Derecho Comunitario Europeo, n 24, mayo-agosto, 2006, p. 596.

${ }^{84}$ Ibidem, p. 595.

${ }^{85}$ Verdú Baeza, J., «Un acuerdo insuficiente», ElPaís, 23.03.2006. Disponible en: http://www.cat. elpais.com/diario/2006/03/23/andalucia/1143069737 850215.html [Visto el 11/11/2020]. 
La Mancomunidad de Municipios del Campo de Gibraltar, que contribuyó a aunar esfuerzos y coordinó buena parte de las acciones institucionales contra dicha presencia en la zona, se mantuvo en todo momento en contacto e integrada con la plataforma ciudadana creada al efecto y que lideró buena parte de las movilizaciones. Poco más de un mes después de la llegada del submarino averiado, el ente comarcal ya había acordado dirigirse al Gobierno español mostrando su preocupación. Más adelante, y a través del Consejo Consultivo, compuesto por todos los alcaldes de la comarca, había mostrado su total oposición a que las tareas de reparación de tan grave avería se desarrollaran a tan corta distancia de las poblaciones que rodean la bahía de Algeciras.

La corporación comarcal criticó abiertamente a las autoridades del Gobierno español, al considerar que había mantenido una sorprendente actitud ante las decisiones británicas, sin manifestar la más mínima crítica ni oponerse a que el submarino fuera reparado en Gibraltar. Igualmente calificó de desleal al Gobierno británico por «recalificar de forma subrepticia y con alevosía el puerto de Gibraltar para permitir la reparación del submarino en sus muelles».

El grueso de la defensa de la postura gubernamental española la asumió el Ministerio de Asuntos Exteriores y en concreto su titular, Josep Piqué, quien mantuvo al menos tres debates en la Comisión de Asuntos Exteriores del Congreso sobre esta cuestión, donde tuvo que escuchar todo tipo de reproches de los partidos de la oposición ${ }^{86}$. Sin embargo, fue precisamente Piqué quien desde el Gobierno se permitió un solo desahogo en forma de carta a su colega, el titular del Foreign Office, Robin Cook, cuando cinco meses después de la llegada del 'HMS Tireless' a Gibraltar se descubrió que la avería era más grave de lo pensado en un principio. A la fisura de dos milímetros en una tubería del circuito de refrigeración, le siguió un problema de posible fatiga de materiales en varios de los SSN británicos que, inmovilizados en su totalidad, fueron sometidos a revisión.

En la carta en cuestión ${ }^{87}$, el ministro español se quejaba de que la información que recibía era insuficiente y calificaba de inquietante el descubrimiento de que

\footnotetext{
${ }^{86}$ Los debates se produjeron el 26 de septiembre y el 29 de noviembre de 2000 y el 14 de marzo de 2001.

${ }^{87}$ Egirbide, P. y Cembrero, I., «Piqué se queja ahora ante Londres por la escasa información sobre la avería del 'Tireless'», El País, 26.10.2000. Disponible en: https://elpais.com/ diario/2000/10/26/espana/972511228 850215.html [Visto el 10/11/2020]. 
la avería era más grave de lo en principio especulado. Igualmente consideraba alarmante la consecuente prolongación de la estancia del submarino.

La Comisión de Asuntos Exteriores del Congreso debatió y votó el 26 de septiembre de 2000 una Proposición no de Ley del Grupo Socialista ${ }^{88}$ para que el submarino averiado fuera trasladado y reparado en un lugar que reuniera las condiciones necesarias. La propuesta fue rechazada.

El presidente de la Mancomunidad llegó a trasladarse a Estrasburgo, donde asistió en la sede del Parlamento Europeo a un pleno en el que se debatió ésta cuestión. Igualmente, una representación de los alcaldes de la zona se trasladó a Madrid, donde se entregaron escritos en la Presidencia del Gobierno, se reunieron con el ministro de Asuntos Exteriores y se mantuvieron encuentros con los embajadores del Reino Unido y Suecia en España, dado que este último país ostentaba la presidencia de turno de la Unión Europea. El 20 de enero, la mayor manifestación que nunca se había producido en el Campo de Gibraltar recorrió las calles de Algeciras en contra de la permanencia del 'HMS Tireless' en Gibraltar. Entre 20.000 y 60.000 personas, según las fuentes, se reunieron con este motivo ${ }^{89}$.

El 'HMS Tireless' fue dado de baja el 19 de junio de 2014 tras que en febrero de 2013 volviera a sufrir otra fuga de su circuito de refrigeración cuando navegaba cerca de la costa este de Escocia ${ }^{90}$.

\section{Las escalas de los submarinos británicos}

Las escalas de los submarinos británicos en la base de Gibraltar, lógicamente, son más numerosas que las de los submarinos norteamericanos. Parece una obviedad, pero dejemos dicho que no se producen escalas de submarinos británicos en Rota, aunque sí se han producido, con motivo de ejercicios aliados, escalas de buques de superficie de la Royal Navy en la citada base española.

\footnotetext{
${ }^{88}$ Diario de Sesiones del Congreso de los Diputados. Comisión de Asuntos Exteriores. VII Legislatura, $n^{\circ} 55,26 / 09 / 2000$, pp. 1247-1249.

${ }^{89}$ "Miles de personas se manifiestan para exigir el traslado del 'Tireless», El Mundo, 21.01.2001. Disponible en: https://www.elmundo.es/elmundo/2001/01/20/espana/979987170.html [Visto el 09/11/2020].

${ }^{0}$ UK Parliament. Parliamentary Business. Publications and Records, 4.03.2013. Daily Hansard Written Answers. Colum, 846-847W. Disponible en: https://publications.parliament.uk/pa/ cm201213/cmhansrd/cm130304/text/130304w0003.htm [Visto el 17/11/20].
} 
En las dos últimas décadas, las escalas de submarinos británicos en Gibraltar han sumado poco más de sesenta ${ }^{91}$. Si en el caso norteamericano el mayor número de escalas por año se ha mantenido en cuatro y solo en dos ocasiones, en el caso británico la cifra máxima es de ocho escalas en un año, habiéndose producido en dos ocasiones (2015 y 2019), pero esta cifra aparentemente tan elevada tiene una explicación. En ambos casos, cinco de esas escalas las ha protagonizado un solo submarino, que realizó varias entradas y salidas consecutivas, sin duda provocadas por algún mal funcionamiento o pruebas de alguno de sus sistemas, con lo que en realidad la cifra de ocho escalas refleja operaciones de dos o tres submarinos a lo sumo, dado que uno solo realiza cinco en un corto espacio de tiempo.

En tres ocasiones se producen seis escalas en un año, incluidos fondeos y cambio de tripulaciones en tránsito, en 2006, 2013 y 2014. Fueron cuatro escalas los años 2005, 2007 y 2009. Destaca este último año por la circunstancia que todas ellas se refirieron a cambios de tripulación en tránsito, sin entrar a puerto, pero con el apoyo logístico de la base. Con tres escalas solo aparecen en las estadísticas consultadas tres anualidades: 2004, 2016 y 2018. El resto de años se cerraron con una o dos escalas, o sin ninguna, como los años 2002 (el siguiente a la marcha del 'HMS Tireless'), 2010 y 2012, así como 2020, en el que ni antes ni durante la pandemia ha entrado en Gibraltar ningún submarino británico.

La mayoría de las escalas de los submarinos británicos ronda la semana y muy rara vez alcanza las dos semanas, aunque si tenemos en cuenta que el 'HMS Talent' entró y salió cinco veces entre el 25 de abril y el 25 de junio de 2019, es decir, en dos meses, quizás podamos convenir que ésta, en realidad, puede considerarse una sola escala, aunque, eso sí, de una duración considerable. Una de estas cinco escalas se prolongó por espacio de 17 días. En esos dos meses permaneció en puerto 24 días. Pero ese mismo año, el 'HMS Ambush' realizó entre el 11 de enero y el 20 de marzo tres entradas, totalizando amarrado a puerto 37 días. En 2015 este mismo submarino protagonizó las otras cinco escalas antes mencionadas, de las cuales cuatro se agruparon entre el 21 de mayo y el 29 de junio.

La Royal Navy mantiene su base avanzada en Gibraltar porque le ofrece una posibilidad de diversificar sus lugares de atraque y reparación de submarinos,

${ }^{91}$ Véase supra, nota 55 para una explicación de las fuentes. 
además de avituallamiento, en una zona de innegable interés estratégico a caballo entre el Atlántico y el Mediterráneo. Además, en Gibraltar los submarinos británicos se encuentran mil millas más cerca de sus zonas de operaciones y de adiestramiento ventajoso en el mar de Alborán, tradicionalmente utilizado para sus ejercicios dadas sus excelentes condiciones meteorológicas. Por estos motivos, entre otros, el Reino Unido no renuncia a las escalas de sus submarinos nucleares en Gibraltar.

\section{LOS PLANES DE EMERGENCIA Y LA POBLACIÓN CIVIL}

Cuando se habla de energía nuclear surge de forma inexorable el asunto de la seguridad en su explotación y de las consecuencias para la población y el medio ambiente de cualquier fuga, accidente o mal funcionamiento de sus dispositivos. En España, a raíz de la construcción de las centrales nucleares de producción de energía eléctrica, se pusieron en marcha, además de los planes de emergencia interior de cada central, los denominados Planes de Emergencia Nuclear Exterior que prevén la actuación que debe materializarse para proteger a las poblaciones residentes en las proximidades de dichas centrales y en los que tienen un papel protagonista los respectivos ayuntamientos sitos en las proximidades. Estos planes prevén desde los avisos a la población, el confinamiento o la evacuación de los ciudadanos según los distintos niveles de la emergencia que se produzcan y la distancia a la que se encuentren de la central $^{92}$. Además, se programan y realizan simulacros periódicos que sirven para concienciar e instruir a la población y a los servicios de emergencia para que, llegado el caso, tengan asumidas determinadas pautas de actuación.

Básicamente esto es lo que no existe en los casos de Gibraltar y Rota que, sin contar con centrales nucleares, sí reciben reiteradamente la visita de submarinos que en su interior cuentan con una pequeña central nuclear productora de energía que es la que mueve y permite el funcionamiento de

${ }^{92}$ El 20 de octubre de 2009 se aprobaron los Planes Directores de los distintos Planes de Emergencia Nuclear Exterior de las centrales nucleares existentes en España, para amoldarlos al nuevo Plan Básico de Emergencia Nuclear, también de 2009. En la actualidad restan en funcionamiento en España cinco centrales nucleares, con siete grupos activos. Como referencia citaremos el Plan Director del Plan de Emergencia Nuclear Exterior de las Centrales Nucleares de Ascó y Vandellós, Tarragona (PENTA), de 20 de octubre de 2009, que tiene una extensión de 69 páginas de BOE. Boletín Oficial del Estado de 10 de noviembre de 2009. Disponible en: https://www.boe.es/eli/es/res/2009/10/20/(4)/dof/spa/pdf [Visto el 12/11/2020]. 
dichos navíos. En el caso de Gibraltar en realidad sí existe un plan de emergencia exterior, pero exclusivamente limitado al interior del territorio que permanece bajo soberanía británica, lo que habitualmente se denomina zona I, de dos kilómetros de diámetro, y no por lo que se refiere al resto de poblaciones de la bahía de Algeciras, ni siquiera al municipio de La Línea de la Concepción que simplemente se encuentra separado del muelle sur de la base gibraltareña por poco más que esa distancia.

\section{Plan de respuesta ante una emergencia radiológica en Gibraltar}

La sexta versión en vigor del 'Gibraltar Radiation Emergency Response Plan', Plan de Respuesta ante una Emergencia por Radiación en Gibraltar, data de 2016 y se encuentra disponible en la web del Gobierno de Gibraltar, en concreto en la de su Agencia de Medioambiente ${ }^{93}$.

Este plan, elaborado por el Gobierno local, está basado y tiene en cuenta el Plan de Respuesta ante Incidentes Mayores del propio Gibraltar y también el Plan de Emergencia interior del operador nuclear, en este caso la base naval.

El objetivo de este plan exterior es el de proteger a la población de Gibraltar ante cualquier incidente «que implique la liberación de productos de fisión radioactivos asociados con una planta de energía nuclear a bordo de un buque de propulsión nuclear». Los redactores del plan han querido señalar que «el riesgo de liberar productos de fisión radiactivos desde un buque de propulsión nuclear por el incidente de su reactor se considera remoto».

Sin embargo, si se produjera un incidente de este tipo, el plan deja claro que en el interior de la base la responsabilidad es absoluta del Ministerio de Defensa y que el exterior quedaría bajo el control de la policía de Gibraltar, en representación del Gobierno local, a la que darían aviso las autoridades militares en caso de producirse un incidente de este tipo.

En el documento se categorizan las alertas que se pueden producir y las actuaciones a desarrollar según cada una de ellas, que van desde la activación del plan de emergencia, pero sin necesidad de implementarlo, hasta el confinamiento de la población con la movilización de todos los servicios de emergencia y la distribución de pastillas de yodo entre la población, para lo cual se mantienen las correspondientes reservas.

${ }^{3}$ Véase Gibraltar Radiation Emergency Response Plan, HM Government of Gibraltar, 2016. Disponible en: http://environmental-agency.gi/wp-content/uploads/2019/10/GibraltarRadiation-Emergency-Response-Plan.pdf [Visto el 23/10/2020]. 
En el centenar de páginas de que consta el plan, en ninguna de ellas se cita ni una sola vez la conveniencia, posibilidad o necesidad de contactar o informar a las autoridades españolas del otro lado de la verja, sea cual sea el grado de emergencia que se declare. Solo en una ocasión, cuando se refiere a la distribución de pastillas de yodo para paliar el efecto de la radiación, se indica que se deben proporcionar «en los puntos de entrada/salida (frontera terrestre/ aeropuerto/puerto)» de Gibraltar.

El plan prevé habilitar para los no residentes, visitantes y turistas, refugio temporal en caso de confinamiento, que deberá mantenerse en todo caso hasta que las autoridades indiquen lo contrario, permaneciendo atentos a las informaciones que se transmitirán por los medios de comunicación locales. De hecho, el plan contempla la «abrumadora atención internacional» que despertará un incidente que involucre a un reactor nuclear en un buque de guerra, por lo que se ha de estar «preparado para atender las demandas de los medios de comunicación» que comenzarán a llegar de forma inmediata y podrían sumar más de un centenar a las pocas horas de iniciado el incidente. La posibilidad de que se restrinja el acceso por la verja solo retrasaría brevemente el acceso de la prensa, señala el plan.

Quien sí aportó algunas concreciones respecto a compartir información con las autoridades españolas en caso de accidente fue el ministro Jack Straw, en la carta ya citada que dirigió en 2006 a su colega Miguel Ángel Moratinos, en la que señalaba que el Gobierno británico ofrecía al Gobierno español las mismas garantías que se ofrecían cuando un submarino nuclear recalaba en un puerto extranjero y le adjuntaba copia de la Statement by the United Kingdom Gobernment on Operation of Nuclear Powered Warships in Foreign Ports (Declaración del Gobierno del Reino Unido sobre la operación de buques de guerra de propulsión nuclear en puertos extranjeros).

Aunque el ministro británico reconocía que esta declaración no sería aplicable a España, dado que no es el anfitrión de las escalas en Gibraltar, ante las especiales características de este caso y la demanda efectuada, el ministro británico confirma una serie de puntos comprometiéndose a llevarlos a cabo. Esas seguridades dadas en 2006 seguían siendo válidas para el Gobierno español en 2018, dado que las reprodujo por escrito en una respuesta parlamentaria al diputado Miguel Ángel Heredia.

Según interpretaba el Ejecutivo español esas seguridades en 2018, 
hay un entendimiento entre el Reino Unido y España por el cual el Reino Unido se compromete a:

- Declarar todos los buques submarinos a través de los mecanismos OTAN pertinentes,

- Advertir al Gobierno español de todos los movimientos de submarinos británicos en la zona de Gibraltar,

- Ofrecer las máximas garantías de seguridad pública y medioambiental de sus buques, incluyendo el compromiso oficial de no permitir la descarga de ningún material peligroso y de no establecer un centro de reparación de averías graves en Gibraltar,

- Informar de manera inmediata en el caso de la eventualidad de un accidente que pueda afectar a un buque de la Royal Navy de escala en Gibraltar ${ }^{94}$.

La literalidad de la carta en este último punto apuntaba que el Reino Unido se comprometía a notificar «de inmediato y trabajar en colaboración con todas las autoridades competentes, en el caso muy improbable de un accidente que afecte al reactor de un navío de guerra que fuera a llevar a cabo una escala en el puerto de Gibraltar» ${ }^{95}$.

Pero para que esa colaboración en caso de accidente pudiera resultar provechosa, en el lado español de la Verja debería existir algún tipo de plan elaborado y probado que permitiera, primero, que la población estuviera informada de la posibilidad de que se concrete ese riego y tener al menos referencia de las medidas que debería adoptar, así como de los canales por los cuales el Gobierno le informaría de dicha eventualidad. Nada de esto existía, ni existe hoy en día, como muy bien saben los alcaldes de la zona.

Cuando la Junta de Andalucía sometió a información pública su proyecto de Plan Territorial de Emergencia de Andalucía, en 2011, el grupo Verdemar-Ecologistas en Acción presentó una serie de alegaciones en las que ${ }^{94}$ Ver pregunta al Gobierno para ser contestada por escrito, Registro de Entrada no 50708 de 11.10.2017 en, http://www.congreso.es/entradap/112p/e5/e 0050708 n 000.pdf y respuesta del Gobierno por escrito, Registro de Entrada no 68493 de 10.01 .2018 en, http:// www.congreso.es/entradap/112p/e6/e 0068493 n 000.pdf [Vistos el 22/11/2020].

${ }^{5}$ Citado en Romero Bartumeus, L., «Lo estratégico en la cuestión...» cit. nota 80. Los originales y las traducciones de las cartas que se intercambiaron Straw y Moratinos, así como otros documentos de la época referidos a Gibraltar, estuvieron disponibles en su momento en la web del Ministerio de Asuntos Exteriores español. Hoy no lo están. La carta de 27.02.2006 de J. Straw y el Statement anexo, así como la Carta de respuesta de M. A. Moratinos de 08.03.2006 pueden verse como los documentos 25 y 26 en el Anexo Documental de la obra de GonzÁLEZ Garcia, I. y Del Valle Gálvez, A., Gibraltar y el Foro tripartito de Diálogo, Dykinson, Madrid, 2009 , en pp. 514 y 517 respectivamente. 
fundamentalmente se refería a distintas cuestiones que afectaban al polígono industrial de la Bahía, pero en las que también se recordaba la existencia de una base militar en Gibraltar «donde se reparan y llegan submarinos de propulsión nuclear» y que nada se preveía ante una posible emergencia nuclear. La alegación no recibió respuesta.

En septiembre de 2017, los diputados del Grupo Socialista Miguel Ángel Heredia y Salvador de la Encina, presentaron una Proposición no de Ley en el Congreso de los Diputados ${ }^{96}$ relativa a la formulación de Planes de Emergencia específicos sobre radiación nuclear para los municipios de las bahías de Algeciras, Cádiz y Rota ante la posibilidad de una fuga radioactiva procedente de un submarino.

Los diputados argumentaban que, ante la presencia evidente de submarinos de propulsión nuclear en las bases de Gibraltar y Rota, «sólo los gibraltareños saben a qué riesgos se exponen y cómo evitarlos», aludiendo a que solamente ellos contaban con un Plan de Emergencia para tal caso. Sin embargo, añadían, «los alcaldes españoles de ambas comarcas desconocen todo sobre un posible accidente», disponiendo solamente de marcos genéricos sin que ni siquiera los servicios de emergencia próximos tengan instrucciones ni conozcan qué medidas deberían adoptar.

Su petición se concretaba en la puesta en marcha de Planes de Emergencia Específicos sobre la radiación nuclear en las citadas zonas próximas a las bases militares citadas y, además, solicitaban gestiones diplomáticas ante el Reino Unido «para que Gibraltar cese como base de submarinos nucleares». Esta Proposición no de Ley nunca llegó a debatirse en sede parlamentaria, decayendo tras la disolución de la XII Legislatura de las Cortes.

En fecha muy cercana a la proposición anterior, el diputado Miguel Ángel Heredia presentó una pregunta al Gobierno, cuya respuesta ya hemos referenciado con anterioridad en parte ${ }^{97}$, en la que preguntaba si tenía pensado poner en marcha Planes de Emergencia Específicos sobre radiación nuclear en las bahías de Algeciras, Cádiz y Rota; si estaba el Gobierno llevando a cabo gestiones para que Gibraltar dejara de ser base de submarinos nucleares o contemplaba esa posibilidad a corto o medio plazo. En su respuesta, el

\footnotetext{
${ }^{96}$ Diario Oficial de las Cortes Generales. Congreso de los Diputados. Serie D, no 224, de 6 de octubre de 2017, pp. 8 y 9.

${ }^{97}$ Véase nota 94.
} 
Ejecutivo no aportaba ninguna novedad reseñable, más allá de recordar que el Plan Estatal de Protección Civil ante el Riesgo Radiológico contempla la elaboración de una serie de Planes de Coordinación y Apoyo para su aplicación en emergencias de interés nacional o en apoyo de los planes autonómicos. Este plan de apoyo, decía el Gobierno, tendrá por finalidad, en coordinación con el Plan de Emergencia Nuclear de la Armada (PENAR) ${ }^{98}$, establecer los procedimientos para la gestión de las emergencias que se produzcan en las bases y fondeaderos navales incluidos en el citado PENAR. Anunciaba que se había creado un grupo de trabajo coordinado por el Ministerio del Interior y que se había reunido ya varias veces.

El Gobierno español señalaba igualmente en esta respuesta que

el atraque de buques de Estado británicos de propulsión nuclear en el puerto de Gibraltar se deriva del uso militar de las instalaciones portuarias conforme a la cesión por el Tratado de Utrecht del puerto de Gibraltar a la Corona de Gran Bretaña y no tiene carácter permanente. Así, no puede afirmarse -añade- que la entrada puntual de un buque de la Armada Británica, cualquiera que sea la energía empleada para su navegación, contravenga el Tratado.

Considerar entrada puntual las cifras y circunstancias que hemos ido aportando más arriba es, como poco, una muestra de cinismo que ningún representante gubernamental debería permitirse en sus comunicaciones con el Parlamento.

Finalizaba la respuesta recordando el contenido que en materia de seguridad ofreció el ministro británico Jack Straw en 2006 a su homólogo español, calificándolo como «un entendimiento» entre Estados, por el cual el Reino Unido adquirió una serie de compromisos que ya hemos señalado más arriba.

Con fecha 18 de enero de 2018 el mismo diputado, al que se le unió su compañero de grupo Salvador de la Encina, presentaron una batería de tres preguntas parlamentarias para ser respondidas por escrito ${ }^{99}$ y que insistían, por este orden: en la fecha prevista para contar con un documento que sirva para coordinar los casos de emergencia en las zonas próximas a los atraques de submarinos nucleares; en la causa del retraso en situar la fecha para poner en marcha los planes de emergencia específicos sobre radiación nuclear en las

${ }^{98}$ Del PENAR hablaremos más adelante, pero se trata de un Plan de Emergencia Nuclear Interior de las bases y fondeaderos donde están autorizados a recalar submarinos nucleares.

${ }^{99}$ Boletin Oficial de las Cortes Generales. Congreso de los Diputados. Serie D, no 291, 05.02.2018, p. 100. Preguntas 70765, 70766 y 70767. 
mismas zonas y, por último, por qué no responde el Gobierno si está llevando a cabo gestiones diplomáticas para que Gibraltar cese su actividad como base de submarinos nucleares.

El Gobierno agrupó las respuestas a estas tres preguntas en dos, que en realidad eran, por mitades, la misma respuesta que la que había facilitado con fecha 10 de enero a Miguel Ángel Heredia ${ }^{100}$. No aportan por tanto ninguna novedad, es más, reproducen casi literalmente por mitades el contenido de la anterior.

\section{El Plan de Actuación español ante la visita del 'HMS Tireless'}

Lo que el Gobierno español puso en marcha para proteger a la población del Campo de Gibraltar con motivo de la estancia del 'HMS Tireless' durante prácticamente un año en Gibraltar, reparando la avería del circuito primario de refrigeración de su reactor, es lo más parecido que ha tenido la zona de la bahía de Algeciras a un Plan de Emergencia Exterior Nuclear, sin serlo.

En realidad, lo que el Gobierno implementó, como el ministro de Exteriores recordó varias veces en sede parlamentaria ${ }^{101}$, fue un Plan de actuación ante un posible incidente/accidente durante la estancia del submarino nuclear 'Tireless' en Gibraltar. La explicación dada fue que el Consejo de Seguridad Nuclear (CSN) y las autoridades de Protección Civil españolas no creyeron preciso elaborar un plan de emergencia, dado que el reactor se encontraba desde hacía tiempo parado, en condiciones seguras y con una muy baja tasa de generación de calor residual. Por estas circunstancias, se entendió que solamente existía necesidad de preparar una actuación de respuesta a emergencias urgentes en un radio de 2 kilómetros en torno al submarino y esa área caía íntegramente dentro del territorio gibraltareño. Fuera de esa zona no eran necesarias medidas protectoras urgentes, solo se necesitaba una vigilancia radiológica hasta un radio de 10 kilómetros, que sí incluía territorio español y fue la que se implementó.

Siguiendo las explicaciones dadas por el ministro de Exteriores en sus tres comparecencias antes reseñadas, se constituyó un Comité Asesor del Plan de Actuación. Así mismo, se conformó un Grupo Mixto hispano-británico,

\footnotetext{
${ }^{100}$ Ver respuestas del Gobierno por escrito, Registro de Entrada no 78922 , de 08.03.2018 en, http://www.congreso.es/entradap/112p/e7/e 0078922 n 000.pdf y Registro de Entrada n ${ }^{\circ}$ 86583, de 25.04.2018 en, http://www.congreso.es/entradap/112p/e8/e 0086582 n 000.pdf [Vistas el 22/11/2020].

101 Véase nota 86.
} 
formado por técnicos, que se reunía cada quince días. Por parte española participaban en este grupo el CSN, la Dirección General de Protección Civil y los ministerios de Asuntos Exteriores, Defensa y Portavoz del Gobierno. Se estableció un punto de contacto permanente entre los dos gobiernos y un esquema de comunicación igualmente permanente. El Plan de Actuación contaba con una 'interfase' con el Plan de Emergencia de Gibraltar.

El CSN, según explicó el ministro, estaba en contacto permanente y recababa información del Panel Regulador Nuclear de la Royal Navy, que era la autoridad responsable del lado británico. Este contacto directo entre autoridades técnicas nucleares de ambos países lo confirmó el propio CSN en su informe anual dirigido al Parlamento ${ }^{102}$, añadiendo que de sus colegas británicos recibieron información tanto de los aspectos de seguridad nuclear, como de la reparación en marcha, incluido el diseño de la misma. De los avances de la reparación se recibían informes diarios y otros semanales sobre el estado del reactor, las previsiones de actividades futuras y de los hitos cubiertos y previstos.

A su vez, con la información que se recibía, el CSN elaboraba informes diarios sobre el programa especial de vigilancia radiológica que se puso en marcha y semanales que eran resúmenes de la información recibida con esa misma periodicidad del Panel Regulador británico

El 3 de noviembre, dos técnicos del CSN, según informó Josep Piqué en la Comisión de Exteriores del Congreso, recibieron autorización para visitar el 'HMS Tireless', aunque tuvieron limitado su acceso a algunas zonas, no pudiendo acceder al recinto del reactor ni al panel de control del mismo. La tecnología que rodea a todo lo nuclear en sus aplicaciones militares cuenta con los máximos niveles de clasificación y no hay que olvidar tampoco que mucha de la tecnología de los submarinos nucleares británicos es compartida con los norteamericanos, por lo que existen acuerdos de confidencialidad mutua en esta materia. De hecho, el Acuerdo USA-UK de 1958, que ya hemos citado, sobre cooperación nuclear con fines de Defensa, señala expresamente que ninguna de las dos partes podrá comunicar información clasificada o permitir el acceso a equipos puestos a disposición de una de las partes, a cualquiera nación u organismo internacional sin la autorización de la otra parte.

102 Consejo de Seguridad Nuclear, Informe del Consejo de Seguridad Nuclear al Congreso de los Diputados y al Senado. Resumen año 2000, pp. 14 y 15. Disponible en: https://www.csn.es/ documents/10182/13529/Informe+anual+2000+\%28resumen $\% 29$ [Visto el 02/11/20]. 
Esta visita de técnicos españoles al submarino provocó una reacción política airada del ministro principal de Gibraltar, Peter Caruana, quien manifestó públicamente su enfado por esta autorización, que consideró injustificada, de las autoridades británicas, llegando a afirmar que España carecía de derecho alguno para interferir en este asunto. El titular de Exteriores español señaló que, pese a esta queja y a la opinión de «muchos responsables políticos del Reino Unido» en el mismo sentido, el Gobierno británico prefirió actuar «con transparencia, desde el punto de vista de la información y desde el punto de vista de las actitudes perfectamente razonable y de agradecen ${ }^{103}$.

\section{Plan de vigilancia radiológica}

«Desde el mismo día que se tuvo conocimiento de la entrada del submarino» en Gibraltar, afirma el CSN en su informe al Parlamento antes citado, se puso en marcha un programa de vigilancia radiológica en el Campo de Gibraltar, en concreto en la bahía de Algeciras, con medios propios del CSN y de otros organismos.

Durante el tiempo de estancia del submarino, los controles diarios realizados del agua, aire y playas dieron todos unos resultados negativos, es decir, no se detectaron valores de radiación por encima del fondo habitual de la zona.

Los medios de los que dispuso el CSN para llevar a cabo estas mediciones fueron los propios de la institución (Red de Estaciones Automáticas), los de la Armada, que desplazó a la zona a sus equipos GOVRA ${ }^{104}$, los laboratorios del CEDEX $^{105}$ y la Red de Alerta de Radioactividad (RAR) de la Dirección General de Protección Civil.

La Red de Estaciones Automáticas (REA) del CSN, en las fechas que nos ocupan, contaba con 24 puntos de control distribuidos por toda España, más una treintena pertenecientes a cuatro comunidades autónomas a cuyos datos tiene acceso. De todos los anteriores solamente el ubicado en Tarifa se encontraba en las proximidades de Gibraltar. Su finalidad es la vigilancia de la radioactividad en la atmósfera en tiempo real. La REA se está ampliando para contar en un futuro próximo (programa 2019/2021) con 185 estaciones automáticas fijas

\footnotetext{
${ }^{103}$ Diario de Sesiones del Congreso de los Diputados. Comisión de Asuntos Exteriores. VII Legislatura, n $184,14.03 .2001$, pp. 5438.

${ }^{104}$ GOVRA: Grupo Operativo de Vigilancia Radiológica de la Armada. De ellos hablaremos más adelante.

${ }^{105}$ CEDEX: Centro de Estudios y Experimentación de Obras Públicas.
} 
más 15 móviles, con capacidad éstas últimas para actuar sin la dependencia de las fijas en cualquier lugar accesible de la geografía nacional ${ }^{106}$. Cuando esta ampliación esté finalizada, además de la modernización de la estación de Tarifa, en las proximidades del Estrecho se añadirán una en Cádiz y otra en Villamartín (provincia de Cádiz), además de otras tres en Ceuta, Marbella y Málaga ${ }^{107}$.

Además, el CSN cuenta con 15 estaciones de muestreo de aguas costeras para vigilar la calidad de estas desde el punto de vista radiológico. En las proximidades de Gibraltar existen tres estaciones de esta naturaleza, ubicadas en Isla Cristina (Huelva), puerto de Cádiz y estrecho de Gibraltar (sin especificar ubicación exacta) ${ }^{108}$.

Por su parte, la Red de Alerta Radiológica (RAR) de Protección Civil, que suma más de 900 estaciones en todo el territorio nacional, tiene también por finalidad medir de forma automática la radioactividad en la atmósfera, el fondo radioactivo natural y constituir una red para la alerta inmediata. En el Campo de Gibraltar existen seis estaciones de esta red y otras siete en las proximidades el Estrecho. En la comarca existen estaciones de la RAR en Los Barrios, San Roque, La Línea, Algeciras (2) y Tarifa. Además hay estaciones en Barbate y Ceuta, a las que se suman, solo por citar las más cercanas, las de Estepona, Marbella, Fuengirola, Torremolinos y Málaga ${ }^{109}$.

Todas las mediciones realizadas en torno a la bahía de Algeciras durante el año que permaneció el 'HMS Tireless' reparando, llevaron a las autoridades españolas a afirmar que no hubo emisión radioactiva alguna al medio ambiente. Por su parte, el CSN dejó escrito y comunicado al Congreso y al Senado que «desde el punto de vista técnico se ha confirmado la ausencia de riesgo para la población de la zona, tal como fue manifestado reiteradamente».

${ }^{106}$ Consejo de Seguridad Nuclear, Programas de vigilancia radiológica ambiental. Resultados 2018. Disponible en: https://www.csn.es/documents/10182/27786/INT-04.42\%20Programas $\% 20$ de $\% 20$ vigilancia $\% 20$ radiol $\%$ C3 $\%$ B3gica $\% 20$ ambiental. $\% 20$ Resultados $\% 202018$ [Visto el 09/11/2020].

${ }^{107}$ Romero Bartumeus, L., «El Plan de Emergencia Nuclear de la Armada contempla las escalas de submarinos en Gibraltar (y II)», Noticias Gibraltar, 18.08.2018. Disponible en: https:// noticiasgibraltar.es/noticias/plan-emergencia-nuclear-armada-contempla-escalas-submarinosgibraltar-y-ii [Visto el 16/11/2020].

${ }^{108}$ Consejo de Seguridad Nuclear: Programas de vigilancia ... cit. nota 106.

${ }^{109}$ Dirección General de Protección Civil y Emergencias, Red de Alerta a la Radiactividad (RAR). Informe del tercer trimestre del año 2020. Disponible en: http://www.proteccioncivil.es/ documents/20486/529d2a22-7836-4875-b3ae-216a2e1e9258 [Visto el 14/11/2020]. 


\section{El Plan de Emergencia Nuclear de la Armada (PENAR)}

En julio de 2018 se renovó el Plan de Emergencia Nuclear de la Armada (PENAR), que se encuentra accesible en la web de esta institución ${ }^{110}$. Sustituyó al anterior, que databa de 1988, una vez que el CSN lo validó.

Como ya hemos mencionado, el PENAR es un Plan de Emergencia Nuclear Interior que solamente diseña las medidas a adoptar en el interior de las bases navales españolas que pueden verse afectadas por la presencia de buques de propulsión nuclear de visita en las mismas o sus fondeaderos.

El Gobierno tiene restringida dicha posibilidad de arribada de buques con propulsión nuclear a tres localizaciones: Rota, Cartagena y Porto Pi (Palma de Mallorca). Solo en Rota es posible el atraque (en el muelle 1) y el fondeo de buques de propulsión nuclear, mientras que en las otras dos solamente está prevista la autorización de fondeo, previa solicitud.

El Plan Estatal de Protección Civil ante el Riego Radiológico ${ }^{111}$ contempla en su artículo 5.7 la existencia de un Plan de Coordinación y Apoyo del citado Plan Estatal con el PENAR. Dicho Plan de Coordinación tendrá por finalidad la organización y los procedimientos que garanticen la gestión de emergencias que se originen en las bases y fondeaderos navales incluidos en el PENAR.

Si bien el PENAR debe implementarse exclusivamente en esas tres bases españolas antes citadas, sin embargo hasta en cinco ocasiones aparece citada en las ocho páginas de que consta dicho Plan la base británica de Gibraltar. Recuerda el PENAR, en su primera página, que el Ministerio de Defensa ordenó al AJEMA, con motivo de la llegada averiado del 'HMS Titreless' en mayo de 2000: «adoptar para Gibraltar las mismas medidas que están en vigor en Rota, Cartagena y Palma de Mallorca en cuanto a la utilización de los GOVRA. Por tanto, la escala ocasional de submarinos de propulsión nuclear en Gibraltar hace necesario desplegar los equipos GOVRA en Algeciras», para tomar muestras de agua de mar, sedimentos y moluscos vivos. Más adelante, al hablar de los riesgos y en la página 3, el PENAR reitera, por si no hubiera quedado claro, que «cada vez que fondea o entra un submarino nuclear en

${ }^{110}$ Armada Española, Plan de Emergencia Nuclear de la Armada (PENAR), Disponible en: https:// armada.defensa.gob.es/ArmadaPortal/page/Portal/ArmadaEspannola/mardigitaldocinstituc/ preflang-es/00docu-institucional-armada+--10penar [Visto el 16/11/2020].

${ }^{111}$ Real Decreto 1054/2015 de 20 de noviembre. Boletin Oficial del Estado, n 279, de 21.11.2015. Disponible en: https://www.boe.es/buscar/pdf/2015/BOE-A-2015-12571-consolidado.pdf [Visto el 16/11/20]. 
Gibraltar, un equipo GOVRA se desplegará en Algeciras para efectuar las mediciones correspondientes, práctica que no tiene que comportar a priori ninguna declaración de emergencia».

Durante los doce meses en que el submarino británico permaneció en el puerto de Gibraltar, los GOVRA se mantuvieron desplegados en la bahía de Algeciras tomando muestras tres veces al día. Desde entonces, cada vez que un submarino nuclear británico o norteamericano recala en Gibraltar, un equipo GOVRA se desplaza al Campo de Gibraltar para realizar las mediciones correspondientes. De igual forma, desde 1988 se adoptan medidas similares cada vez que un submarino norteamericano recala en Rota, con lo que se garantiza contar con información propia y permanente de la calidad de las aguas de la zona cercana a los atraques de submarinos nucleares.

Los GOVRA son los equipos especializados de la Armada encargados de la toma de muestras para detectar la posible radiación ambiental ante un posible riesgo radiológico en instalaciones de la Armada y en el caso de las escalas de submarinos nucleares en Gibraltar y en Rota. Estos equipos se crean en 1988 tras la promulgación ese año del primer Plan de Emergencia Radiológica de la Armada y su primera intervención se produce precisamente ese año, en la base naval de Rota ${ }^{112}$. El equipo está compuesto por un oficial y seis suboficiales, pertenecientes a unidades radicadas en la base con formación específica que, como mínimo, consiste en el Curso de Vigilancia Radiológica de la Armada, aunque también lo forman integrantes con el curso de especialista en $\mathrm{NBQ}^{113}$, supervisor de instalaciones radiológicas o el curso de operador de instalaciones radiológicas.

La activación de estos equipos, en el caso de las escalas en Gibraltar, está prevista en otro documento de la Armada, el Plan de Vigilancia Radiológica Ambiental de la Armada, de 20 de diciembre de 2013. Ante cualquier incidente radiológico que el GOVRA pudiera detectar en estos casos, la Armada lo pondría en conocimiento de forma inmediata de las autoridades competentes, a través de su cadena de mando, y que incluyen la Sala de Emergencias del CSN, la Delegación del Gobierno y la Unidad Militar de Emergencias. Correspondería

${ }^{112}$ Agradezco al coronel Manuel Pérez García, jefe de la Oficina de Relaciones con la Prensa (ORP) de la Armada en Rota, que me facilitara, con fecha 26.11.2020 y por correo electrónico, las respuestas a un cuestionario que previamente le remití sobre el funcionamiento de los GOVRA y de cuyo contenido he extraído una parte de la información sobre esta unidad.

${ }^{113}$ NBQ: Nuclear, Bacteriológico y Químico. 
a los organismos de Protección Civil activar cualquier medida en beneficio de la población circundante, no a las autoridades militares.

El PENAR, dado su carácter de plan de emergencia interior, solo se aplicaría en el interior de la Base Naval de Rota, del Arsenal de Cartagena y de la Estación Naval de Porto Pi. La gestión de cualquier emergencia radiológica en las aguas territoriales españolas es responsabilidad del Ministerio de Fomento, a través de la Dirección General de la Marina Mercante, tal y como recoge el PENAR. Y la aplicación de cualquier plan de emergencia en la zona terrestre ajena a las bases, pero colindante con las instalaciones navales antes mencionadas, correspondería a las autoridades de Protección Civil, dependientes del Ministerio del Interior y de las Comunidades Autónomas.

El Real Decreto que aprobó la Directriz Básica de Planificación de Protección Civil ante el Riesgo Radiológico ${ }^{114}$ confiere al titular de la instalación que pueda dar lugar a una situación de emergencia por riesgo radiológico la responsabilidad de informar con celeridad a los organismos competentes (artículo 5). Además, en su artículo 6, confiere a las administraciones públicas que correspondan la elaboración de los planes de protección civil frente a cualquier riesgo radiológico y que deberían activarse ante la comunicación de su existencia.

La misma Directriz, en el Anexo I, clasifica las posibles emergencias en grupos, según la actividad a la que esté asociada. En el Grupo II de Emergencias Radiológicas se incluye el origen de la misma en «reactores nucleares de potencia inferior a $100 \mathrm{Mw}$ (Megavatios) empleados en buques de propulsión nuclear», cuyas emisiones tienen «muy baja probabilidad de superar los umbrales de dosis correspondientes a la aparición de efectos deterministas graves sobre la salud de las personas».

El PENAR afirma que «la probabilidad de un accidente con consecuencias radiológicas en un reactor nuclear de un buque de guerra occidental es muy remota». De todas formas, no es descartable que se produzca «un escape radioactivo que podría afectar a zonas próximas al buque accidentado y a la zona a sotavento», añade el mismo documento.

El PENAR asume que, dentro de la base gibraltareña y en caso de accidente, se aplicaría el plan interno del Ministerio de Defensa Británico y el

${ }^{114}$ Real Decreto 1564/2010, de 19 de noviembre. En Boletín Oficial del Estado, no 281 de 20/11/10. Ver, https://www.boe.es/boe/dias/2010/11/20/pdfs/BOE-A-2010-17808.pdf [Visto el 16/11/2020] 
externo de Gibraltar, sin que se cite ningún tipo de colaboración o protocolo de conexión con las autoridades españolas si se produjera una emergencia de esas características. El mismo documento reconoce, sin embargo, que «un accidente radiológico en esta base afectaría a la bahía de Algeciras y a las poblaciones cercanas».

Los submarinos que habitualmente visitan la Base Naval de Rota, al igual que los que lo hacen a la de Gibraltar, cuentan con un reactor de potencia inferior a $50 \mathrm{Mw}$ (Megavatios), incluidos por tanto en el Grupo II de Emergencias Radiológicas, según la Directriz Básica antes mencionada, por lo que sus emisiones en caso de accidente tienen «muy baja probabilidad de superar los umbrales de dosis correspondientes a la aparición de efectos deterministas graves sobre la salud de las personas», afirma el PENAR.

Cosa distinta son los reactores de los portaaviones de propulsión nuclear que pueden llegar a fondear en aguas españolas, que suelen contar con una potencia superior a los 100 Megavatios y, por ello, si se produjera una incidencia se incluirían en el Grupo I de Emergencias Radiológicas. Sus emisiones sí podrían producir «efectos deterministas graves sobre la salud si no se toman las correspondientes medidas de protección».

En el PENAR se afirma que, en caso de accidente, el personal situado dentro de un radio de unos 500 metros «se vería afectado por la radiación». El mayor riesgo residiría en el aumento de la tasa de radiación ambiental y de las partículas transportadas por el aire. La contaminación de las aguas próximas igualmente se plantea como posibilidad, aunque a continuación niega que «un reactor de potencia» pueda comportarse como una bomba nuclear «por lo que la probabilidad de que se produzca una explosión de este tipo en el reactor es nula».

El PENAR establece la obligación que tiene el comandante del buque de comunicar la emergencia inmediatamente a su cadena de mando a través de los canales establecidos.

Según la información oficial facilitada por la ORP de Rota al autor, hasta la fecha $(26 / 11 / 20)$ «no se han dado casos positivos de contaminación radiactiva en submarinos nucleares británicos ni norteamericanos» en las bases de Gibraltar y Rota desde que los GOVRA realizan las mediciones durante sus escalas. En Gibraltar, las mediciones comenzaron en 2000, con la llegada del 'HMS Tireless' averiado y desde entonces se han realizado 80 mediciones en la 
bahía de Algeciras. En Rota, las mediciones de los GOVRA comenzaron, como ya hemos señalado, en 1988 y se han realizado hasta la fecha 170 mediciones. Con todas ellas se conforma un archivo histórico de muestreo de ambas zonas.

\section{CONCLUSIONES}

Los submarinos siguen siendo, a día de hoy, unas plataformas a las que no están dispuestas a renunciar las marinas de los países con intereses vitales ligados a la navegación. Las potencias que sostienen su fuerza submarina en la propulsión nuclear no van a renunciar tampoco a las ventajas que esta les proporciona en cuanto a velocidad y capacidad de permanecer largos periodos de tiempo en inmersión y, por lo tanto, creando incertidumbre en sus posibles adversarios. Además, buena parte de la disuasión estratégica, basada en la seguridad de un segundo golpe, está sostenida por este tipo de submarinos.

Las bases de Gibraltar y Rota son lo que se suele definir como bases logísticas avanzadas que los submarinos de propulsión nuclear de ataque (SSN) de las flotas británica y norteamericana utilizan de forma regular, como las cifras de escalas en las dos últimas décadas demuestran.

El descanso del personal, el avituallamiento y las reparaciones de elementos no relacionados con la propulsión nuclear son los motivos más usuales de sus visitas, aunque como demostró la estancia de un año del 'HMS Tireless' en Gibraltar, entre mayo de 2000 y mayo de 2001, las circunstancias sobrevenidas pueden modificar lo previamente establecido.

La decisión de la Royal Navy de mantener las escalas en Gibraltar de su flota de submarinos de patrulla por el Mediterráneo y proximidades está fuera de toda duda. Esta voluntad la ponen de manifiesto las autoridades británicas siempre que tienen ocasión, sea quien sea quien se aventure a ponerla en entredicho.

Dada la cercanía de la base de Gibraltar a la española de Rota, donde los submarinos nucleares norteamericanos tienen igualmente fácil entrada y disponen de más facilidades para su estancia, nos lleva a concluir que el mantenimiento de las escalas de los SSN de la US Navy en la base británica no se deben a una necesidad objetiva basada en criterios logísticos u operativos, sino a la especial y profunda relación USA-UK. Esta relación no solo se centra en todo lo referido a lo nuclear, que tiene su origen en las primeras investigaciones que concluyeron con la fabricación de la primera bomba atómica, 
sino que en lo convencional también se aproxima a la intercambiabilidad de recursos, superando la interoperabilidad.

Pese a que los SSN tienen una larga historia de arribadas a estas dos bases, las poblaciones españolas que viven en las proximidades de las mismas, ya sea en la bahía de Algeciras o en la de Cádiz, carecen de los planes de emergencia exterior que requeriría la presencia de estas centrales nucleares a flote, como sí disponen todas las localidades que circundan las centrales nucleares de producción de energía que existen en territorio español.

El Gobierno de Gibraltar cuenta con un plan de emergencia exterior que prevé una posible emisión de radiación a la atmósfera procedente de un submarino atracado a su puerto, pero en ningún lugar de dicho plan se contempla la conexión con las autoridades españolas del otro lado de la verja. Existe un compromiso británico, comunicado por carta desde el Foreign Office al Ministerio de Asuntos Exteriores español, de información inmediata en caso de que se produjera una emergencia durante una de las escalas en Gibraltar.

La Armada española, por su parte, cuenta con un plan de emergencia nuclear interior de la base de Rota, pero tampoco existe un plan de protección civil de las localidades cercanas que prevean un incidente durante las escalas de los submarinos norteamericanos.

Pese a que durante la estancia del 'HMS Tireless', que reparó una avería en el circuito primario de refrigeración de su reactor nuclear, se puso de manifiesto la carencia de un plan de emergencia exterior español, desde 2001 no se ha avanzado en esa materia, al menos que sepan los ayuntamientos y la población colindantes.

La Armada tiene ordenado realizar mediciones del medio marino cada vez que un submarino nuclear recala en Rota y en Gibraltar, para lo cual cuenta con equipos específicamente formados para ello, lo que facilita que en caso de una emergencia el Gobierno español pueda contar con información propia. A esto se suman los dispositivos que en las dos bahías tiene desplegados Protección Civil para la medición de la radiación en la atmósfera.

Este es un asunto que afecta a la seguridad y protección de ciudadanos españoles pero que tiene su origen en buques de marinas de otros países. En el caso de Rota, un convenio acordado entre Estados Unidos y España, y aprobado por las Cortes, otorga a las autoridades españolas la potestad de autorizar o no esas escalas y las condiciones de las mismas. En el caso de Gi- 
braltar no existe posibilidad alguna de contar con una mínima intervención, más allá de la de recibir la información previa de las escalas y el compromiso de aviso llegado el caso de una emergencia. En ninguno de los dos escenarios es previsible que las circunstancias vayan a cambiar a medio plazo. Aunque sí sería deseable que las autoridades de Protección Civil desarrollaran los planes complementarios adecuados, con la colaboración de los municipios colindantes a esas bases, para tener listas las actuaciones en caso de que fueran necesarias.

\section{BIBLIOGRAFIA CITADA}

DEL VALLE GÁLVEZ, A. - GONZÁLEZ GARCÍA, I., (Eds.), Gibraltar. 300 años, Servicio de Publicaciones de la Universidad de Cádiz, 2004.

GONZALEZ GARCIA, I. y DEL VALLE GÁLVEZ, A., Gibraltary el Foro tripartito de Diálogo, Dykinson, Madrid, 2009

HAIN, P., Outside in, Biteback Publishing, Londres, 2012

LIBERAL FERNÁNDEZ, A., Gibraltar: base militar. El interés anglo-americano por el Peñón, Civitas/Thomson Reuters, Pamplona, 2009

MARQUINA BARRIO, A., «La pista de aterrizaje de Gibraltar y la base militar», en Del Valle Gálvez, A. y González García, I., (eds.), Gibraltar. 300 años, Ed. Servicio de Publicaciones de la Universidad de Cádiz, 2004, pp. 177-192.

MARQUINA BARRIO, A., - «La pista de aterrizaje de Gibraltar y la base militar», UNISCI Discussion Papers, no 19 (enero 2009), p. 231. Puede verse en: https://www. ucm.es/data/cont/media/www/pag-72510/UNISCI $\% 20$ DP $\% 2019 \% 20-\% 20$ MARQUINA\%20GIBRALTAR.pdf

PARDO SANZ, R. M., «La política norteamericana de Castiella», en Oreja Aguirre, M. y Sánchez Mantero, R. (Coords.) Entre la Historia y la Memoria. Fernando María Castiella y la Política Exteriores de España. 1957-1969, Real Academia de Ciencias Morales y Políticas, Madrid, 2007

PÉREZ-PRAT DURBÁN, L., «Cuestiones de seguridad y defensa en torno a Gibraltan», en Del Valle Gálvez, A. y González García, I., (eds.), Gibraltar. 300 años, Ed. Servicio de Publicaciones de la Universidad de Cádiz, 2004, pp. 193-210.

ROMERO BARTUMEUS, L., El Estrecho en la política de seguridad española del siglo XX, Imagenta, 2003

ROMERO BARTUMEUS, L., - «La escala del ‘Sceptre’. Aviso a navegantes», Análisis del Real Instituto Elcano, $\operatorname{ARI~n}^{\circ}$ 25, 28.02.2005. Disponible en: http://realinstitutoelcano. 
org/wps/wcm/connect/a7d9f0804f0185cdb9aefd3170baead1/ARI-25-2005-E. pdf?MOD=AJPERES $\&$ CACHEID $=\mathrm{a} 7 \mathrm{~d} 9 \mathrm{f} 0804 \mathrm{f0} 0185 \mathrm{cdb} 9 \mathrm{aefd} 3170 \mathrm{baead} 1$

ROMERO BARTUMEUS, L., «Lo estratégico en la cuestión de Gibraltan», UNISCI Discussion Papers, $\mathrm{n}^{\circ}$ 12, octubre de 2006. Disponible en: https://www.ucm.es/ data/cont/media/www/pag-72529/UNISCIRomero12.pdf

MARINA REAL BRITÁNICA (ROYAL NAVY), Los fundamentos de la Doctrina Marítima Británica. BR18067, Servicio de Publicaciones de la Armada (española)

SUBMARINE INSTITUT OF AUSTRALIA, «The Importance of Submarines to Australiass National Security», Australian Defence Magazine, Camberra, 9.10.2019. Puede verse en: https://www.australiandefence.com.au/defence/sea/theimportance-of-submarines-to-australia-s-national-security

SUPERVIELLE, F., «Drones submarinos: dos escollos por salvan», Global Strategy, 28.10.2020. Puede verse en: https://global-strategy.org/drones-submarinos-dosescollos-por-salvar/

SZONDY, D., «Rising tide: Submarines and the future of undersea warfare»", New Atlas, 05.07.2017. Puede verse en: https://newatlas.com/future-submarinesmodern-warfare/49896/

VADM, R. G., The Role of Submarines in a Maritime Strategy. ASPI Future Submarine Conference, 9.04.2014. Puede verse en: https://www.navy.gov.au/sites/default/ files/documents/CN_ASPI Speech_09April2014.pdf

VERDÚ BAEZA J., «TJCE-Sentencia de 09.03.2006, Comisión/Reino Unido, C-65/04, Tireless - Energía Nuclear y usos militares en el Tratado EURATOM», Revista de Derecho Comunitario Europeo, $\mathrm{n}^{\circ}$ 24, mayo-agosto, 2006, pp. 595-608.

WALKER, M., y KRUSZ, A., «There's a Case for Diesels», Actas US Naval Institute, junio 2018. Puede verse en: https://www.usni.org/magazines/proceedings/2018/ june/theres-case-diesels

WATSON, P., Historia secreta de la bomba atómica, Ed. Crítica, Barcelona, 2020

WIRTZ, J. A., «The SSBN and US Nuclear Strategy: The Future of the Maritime Deterrent), The Future of the Undersea Deterrent: A Global Survey, Australian National University. National Securiry College, 2020. Puede verse en: https:// nsc.crawford.anu.edu.au/sites/default/files/publication/nsc_crawford_anu_edu au/2020-02/the future of the undersea deterrent.pdf

WORCESTER, M., «The Role of the Submarine in the Fight for Naval Supremacy in the Pacific», The Institute for Strategic, Political, Security and Economic Consultancy (ISPSW), Berlín. Puede verse en: https://www.files.ethz.ch/isn/126364/Jan11 $\underline{\text { Role of Submarine.pdf }}$ 


\section{ANEXO I. \\ Escala de submarinos nucleaeres en Gibraltar de 2000 a 2020 — TABLA}

\begin{tabular}{|c|c|c|}
\hline & REINO UNIDO & ESTADOS UNIDOS \\
\hline 2000 & 1 & 0 \\
\hline 2001 & 1 & 3 \\
\hline 2002 & 0 & 0 \\
\hline 2003 & 2 & 3 \\
\hline 2004 & 3 & 1 \\
\hline 2005 & 4 & 2 \\
\hline 2006 & 6 & 3 \\
\hline 2007 & 4 & 4 \\
\hline 2008 & 2 & 4 \\
\hline 2009 & $4^{\prime}$ & 0 \\
\hline 2010 & 0 & 1 \\
\hline 2011 & 1 & 2 \\
\hline 2012 & 0 & 1 \\
\hline 2013 & 6 & 0 \\
\hline 2014 & 6 & 2 \\
\hline 2015 & $8^{*}$ & 0 \\
\hline 2016 & 3 & 2 \\
\hline 2017 & 1 & 0 \\
\hline 2018 & 3 & 2 \\
\hline 2019 & $8^{*}$ & 3 \\
\hline 2020 & 0 & \\
\hline & & \\
\hline
\end{tabular}

Fuente: Elaboración propia. Con información de Ángel Liberal Fernández: «Gibraltar, base de reparaciones de submarinos nucleares». En, Blog General Dávil, 08/05/2019 y la base de datos de Verdemar-Ecologistas en Acción del Campo de Gibraltar, para series enteras, y otras fuentes particulares y propias del autor para periodos cortos o casos puntuales. No se trata de datos definitivos, dado que no hemos podido encontrar información oficial en abierto. Las cifras aportadas son responsabilidad exclusiva del autor.

En todos los casos marcados con (') se produjeron escalas de fondeo o tránsitos por el Estrecho con apoyo de la base sin entrar a puerto. En algún caso, como en USA2005 y UK2009, todas las cifras de escalas fueron en tránsito.

*UK2015: Cuatro de estas escalas corresponden al 'HMS Ambush', sucedidas en poco más de un mes, y una quinta escala del mismo submarino más alejada en el tiempo.

*UK2019: Cinco de estas escalas corresponden al 'HMS Talent', sucedidas en el plazo de dos meses, y otras tres escalas corresponden al 'HMS Ambush', en el plazo de otros dos meses. 


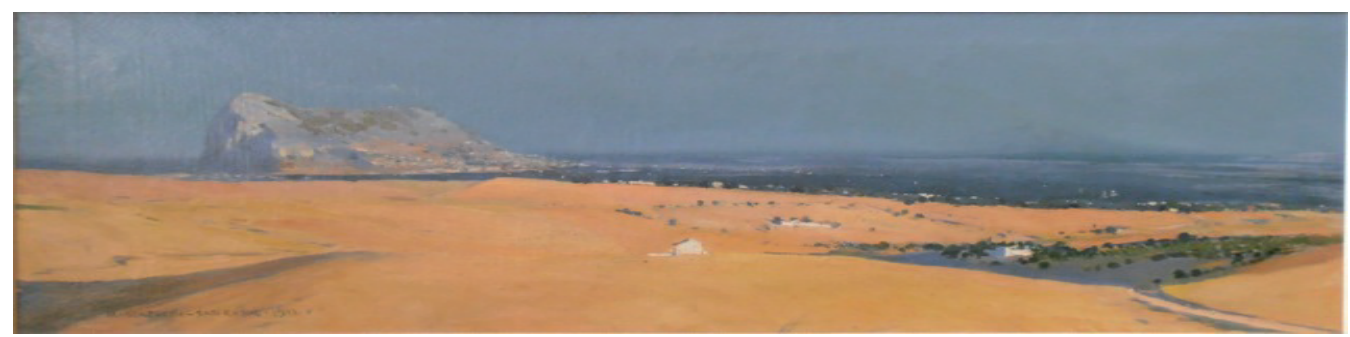

\section{Cuadernos de Gibraltar Gibraltar Reports}

\section{\#04 | 2020-2021}

Sumario

Table of Contents

\section{EDITORIAL}

Alejandro DEL VALLE GÁLVEZ; Inmaculada GONZÁLEZ GARCÍA, Gibraltar after the Brexit: Looking for a New and Imaginative Model of Cross-Border Cooperation in the EU Framework

\section{ESTUDIOS Y NOTAS}

Luis M. HINOJOSA MARTÍNEZ, Los movimientos de capital y los servicios financieros en las relaciones con Reino Unido y Gibraltar tras el Brexit: ¿Seguridad jurídica o ley de la selva?

Luis ROMERO BARTUMEUS, Las escalas de submarinos nucleares en Gibraltar y Rota, y los Planes de Emergencia Radiológica

Facundo D. RODRÍGUEZ, La cuestión de las Malvinas (Falklands) en el Cuarto Decenio Internacional para la Eliminación del Colonialismo

\section{ÁGORA}

Alejandro DEL VALLE GÁLVEZ, Creación de una AECT-Agrupación Europea de Cooperación Territorial- Campo de Gibraltar/Gibraltar (Guía breve sobre planteamiento, requisitos y procedimiento)

Alejandro GARCÍA HEREDIA, El Acuerdo Fiscal entre España y el Reino Unido en relación con Gibraltar

David CHEVASCO, Notes on Contemporary Bilingualism, Llanito and Language Policy in Gibraltar: a Study with a Present-day View of Linguistic Challenges

\section{DOCUMENTACIÓN}

Inmaculada GONZÁLEZ GARCÍA; Alejandro DEL VALLE GÁLVEZ; Lorena CALVO MARISCAL, Juan D. TORREJÓN RODRÍGUEZ:

Documentación I. Naciones Unidas - Gibraltar - Decisiones aprobadas por la Asamblea General de la ONU (2017-2019)

Documentación II. Brexit y Gibraltar - Tratado de Retirada, Protocolo, Tratado Fiscal y MOUs (2018-2020)

Documentación III. España, Brexit y Gibraltar. Declaraciones, Comunicados y Notas de Prensa (2018-2020)

Documentación IV. Andalucía, Brexit y Gibraltar (2018-2019)

Documentación V. Grupo Transfronterizo/Cross-Frontier Group, Memorándum de Entendimiento con el Gobierno de Gibraltar (2017) y Reglamento de Funcionamiento (2018)

Documentación VI. Principio de Acuerdo entre España y el Reino Unido sobre Gibraltar y sobre el Brexit, de 31.12.2020

Documentación VII. Mandato negociador para el Tratado entre el Reino Unido y la Unión Europea con respecto a Gibraltar, 5 de octubre de 2021

\section{LOS ARCHIVOS DE LUIS ROMERO BARTUMEUS}

La descolonización de Gibraltar, de CALVAR, J. - GUERITZ , E. J. - DEL CAMPO, S. - DAVIS H., Ed. Instituto de Cuestiones Internacionales, 1981, 110 páginas, por Luis ROMERO BARTUMEUS

Matar al Mensajero, Vivencias de un «Palomo» en Gibraltar, de TRIAY BOZZINO, J. J. - CASAUS BALAO, J. A., Ed. : Colecciones AUREA, 2000, 198 páginas, por Luis ROMERO BARTUMEUS

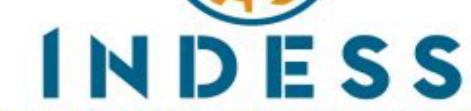

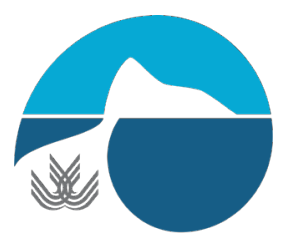

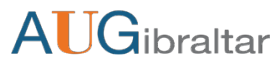

CÁTEDRA JEAN MONNET INMIGRACIÓN Y FRONTERAS DERECHO DE LA UNIÓN EUROPEA $\sim 2$

EDUCACIÓN DE LA UNIÓN EUROPEA

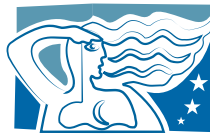

ESTUDIOS

INTERNACIONALES Y EUROPEOS

Centro de Estudios Internacionales y Europeos del Área del Estrecho 